\title{
Facial envelope, labium superior alaeque nasi morpho-physiologic integration and malocclusion
}

\author{
Jacques TALMANT, Joël DENIAUD
}

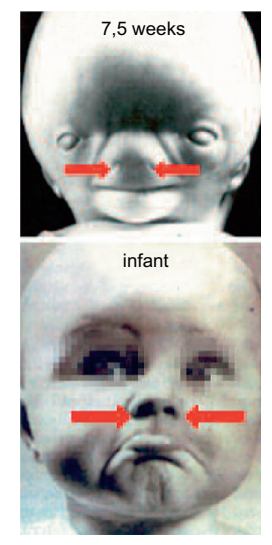

\section{ABSTRACT}

By limiting its objective to correcting dysmorphisms of the dento-alveolar arches, current treatment of malocclusions loses a great deal of effectiveness that technical procedures might otherwise achieve. An inadequate understanding of the mechanics of the facial envelope can allow the dysmorphisms and breathing dysfunctions associated with malocclusions to persist.

However, the oral fissure has a profound impact on the mechanical behavior of the facial envelope. Like an operational command, it transforms the local mechanics of the facial envelope by creating a phenomenon of a concentration of stress and deformations whose manifestations are visible not only on facial soft tissues, but also on their cartilage and osseous supports. This phenomenon also influences the physiology of the facial muscles by distorting them as they are forced to adapt to the fissure, and by guiding the functional adaptations of the envelope.

Basically, the impact of this phenomenon on the structural organization of the facial envelope is transformed by the oronasal morphophysiologic integration of the structures of the face and practitioners must necessarily adapt their therapy to address these problems. Finally, the functional relationship between the nasal mucosa and the cavernous sinus increasingly broadens orthopedic perspectives for therapy that will most importantly encompass the cephalic hypothalamicpituitary axis.

The effectiveness of a procedure appropriately initiated by practitioners of DFO due to their specific expertise will require them to exercise a greater attentiveness to the global functionality of this complex into which the face is integrated.

\section{KEY WORDS}

$\begin{array}{lll}\text { Concentration of stress } & \text { Face } & \text { Mechanics } \\ \text { Swallowing } & \text { Oral fissure } & \text { Soft tissue } \\ \text { Envelope } & \text { Malocclusion } & \text { Breathing }\end{array}$

Conflicts of interest declared by the author: None Article received: 09-2012 
How the facial envelope's contribution to labium superior alaeque nasi morpho-physiologic integration

\section{1 - THE BASIS FOR THIS APPROACH}

Present ideas concerning the development of the face leaves unanswered the question of the mechanical behavior of an envelope whose cutaneous tissue integrally covers the oronasal area: the regulation of the postural activity on the facial muscles of this covering also remains in and of itself an enigma. Therefore, on what basis is it justified for us to think that the dysmorphic area associated with the most common malocclusions is confined to oral structures?

Whatsmore, dysfunctional nasal breathing, by disrupting the thermic interaction related to normal energy exchanges, leads to sleep difficulties that significantly affect memorization and learning ${ }^{23}$. By underestimating how frequently these dysfunctions are associated with malocclusions, are we not misjudging the possible scope of this pathology whose oral symptoms might be concealing a nasal component? And might we not be limiting, in the final analysis, potential therapeutic treatments by neglecting either one and/or another of these symptoms?

\section{1 - 1 - Gaps in our knowledge and therapeutic effectiveness}

The division of the face among distinct medical specialties, regardless by shaping the form of its supports via its rest position, impacts the choice of therapy for malocclusions.

of the respective therapeutic area of each one, has never determined any morphological independence between oral and nasal structures. Their anatomy and physiology show quite the opposite.

The mechanics of the respiratory apparatus that includes the oral and nasal cavities, clearly displays this dependency when, in replenishing the air in the respiratory tract, from the oronasal cavities to the pulmonary alveoli, breathing continually causes morphological responses the modalities of which are multiple but remain profoundly integrated, as this vital oral adaptation contributes to each phase of the cycle depending on the different modalities as they relate to nasal capacities ${ }^{55}$. We should make it clear that here integration designates the process by which the set of signals triggered by breathing that are received by the nervous system, cause a response adapted to the circumstances $^{3}$. During the development and the growth period, breathing itself participates in the expansion of the structures of its region, from the face to the trunk as it passes through the neck. Exercise-induced asthma that certain patients present, in relation to their oral breathing and the bronchoconstriction that comes with it, is only one of the manifestations of this integration.

Oronasal integration demonstrates the sharing by the facial orifices of 
the aerodigestive tract and of the same controlling instruments: for the facial envelope via the orifices of the lips and nose, the soft palate for the isthmus of the throat and the velopharyngeal sphincter. It is also reflected by the extremely delicate coupling of the functioning of these tracts by breathing that paces the EMG activity of the genioglossus muscle during sleep, just as breathing paces the movements of the tongue and of the soft palate as shown by dynamic ultrasound.

The treatment of a malocclusion must combine dentofacial orthopedics with an indispensable optimization of oronasal morpho-physiologic integration $^{60}$. By:

- treating nasal breathing dysfunctions, that cause snoring,

- preventing obstructive sleep apnea, related to repeated vibration trauma to the pharynx and the soft palate ${ }^{59}$,

- re-establishing the energy exchanges of the nasal mucosa that participates in the thermoregulation of the hypothalamic-pituitary axis and in the soundness of sleep.

Within this framework, observing how the development of the upper central incisors mechanically acts on that of the nostril openings, confirms that a single orthopedic procedure can promote the functional relationship between oro-nasal form and function by achieving the optimal shape for the upper airways, including the nostrils, as well as the shape of upper incisor-canine arch. This would then refute the principle that considers the maxillae to be independent from the teeth.

\section{$1-2$ - Mechanics of the oral fissure and morphogenesis of the facial envelope}

According to Farge 19 , "Certain major events in embryonic development are not under the exclusive control of developmental genes any more than they are under the exclusive control of mechanical or hydrodynamic mechanical forces. Rather, they are the product of their interrelationship. The concept of reciprocal action between the genome, proteins and mechanical constraints relating to morphogenesis opens up useful new perspectives in biology as well as in medicine." After the facial buds fuse together, the mechanical influence of an oral fissure on the structural organization of the facial envelope provides a convincing illustration of this phenomenon $^{53}$.

Thus the container-contents relationship between this envelope and its osteodental and cartilaginous supports, maintains their permanent morphogenic relationships by means of the biophysical interactions that it creates (Fig. 1). And even though its orifices influence the shape of this envelope in a very exact manner, the oral fissure is the only orifice that was never closed in the course of development of the ventral wall of the stomadeum; the fissure is therefore the first orifice capable of influencing the mechanics of the envelope when it is subjected to stress, or to put it another way, pre-stressing, by the three-dimensional development of its underlying structures: nasal capsules, 


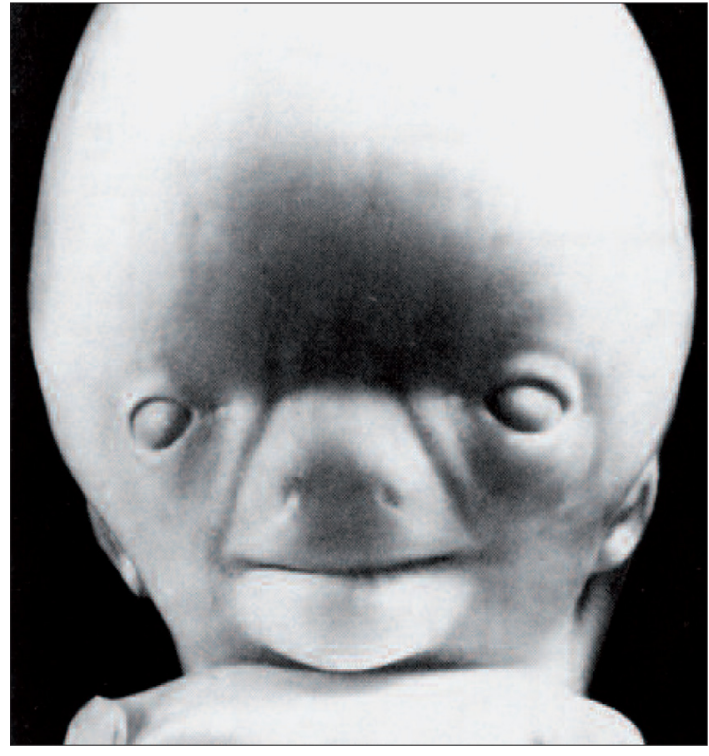

Figure 1

This face of a 7.5-week fetus (after Blechschmidt ${ }^{5}$ ) shows three-dimensional projections of the facial envelope by the development of the nasal capsules, the pre-maxillae that contain the incisors and Meckel's cartilage. Mechanically, by pre-stressing the facial envelope, their local pressures contribute, in all likelihood, to the organization of the facial muscles.

pre-maxillae and its dental contents, and Meckel's cartilage. Moreover, since the oral fissure is only separated from the nostrils by the upper lip, it is important to examine even more carefully the connections underlying their morphological integration. What mechanisms organize the soft tissues bordering the oral fissure and the nostrils? Are genetics the only cause of this? Are there other intervening processes, whose role is not yet sufficiently understood, involving in particular the theater and the modalities of interaction between physics and genetics?

For Blechschmidt": "There is no cell, no tissue and no organ that does not already function from the very beginning of its development." This functioning always depends "... on the length of the stage of growth under consideration and therefore differs over time. Thus, in the course of differentiation, each role changes as much as the form." The early development of the upper central incisor buds therefore raises the question of the role of the succession of their shapes, i.e. the meaning of their growth functions, as this author could have written.

Radlankski's ${ }^{42-44}$ research led him to maintain that the shapes of the lower incisors are subjected to the influences of their immediate environment. Since the contents of the buds are incompressible, they are in effect subject to deformation before their mineralization. According to the Penrose equation ${ }^{37}$ : form $=$ shape + size. Compressing a spherical ball of matter along one of its diameters distorts it into a flattened ellipsoidal shape: its face (reference point for its shape independent of its size) has changed.

It is also possible that at an early stage of development of the upper central incisors $\left(6^{\text {th }}\right.$ week), the increase in volume of their buds subjects them to the sagittal compression of the upper lip that they raise before any mineralization has taken place. By stretching the coronal and mesio-distal diameter of these buds because of the transverse direction of the oral fissure (Fig. 2), this action will widen the pre-maxillae, the oral fissure and nostrils even before the beginning of amniotic breathing ( $11^{\text {th }}$ week). But the nostril openings are enlarged and maintained based on their anatomical proximity to the crypts housing the 


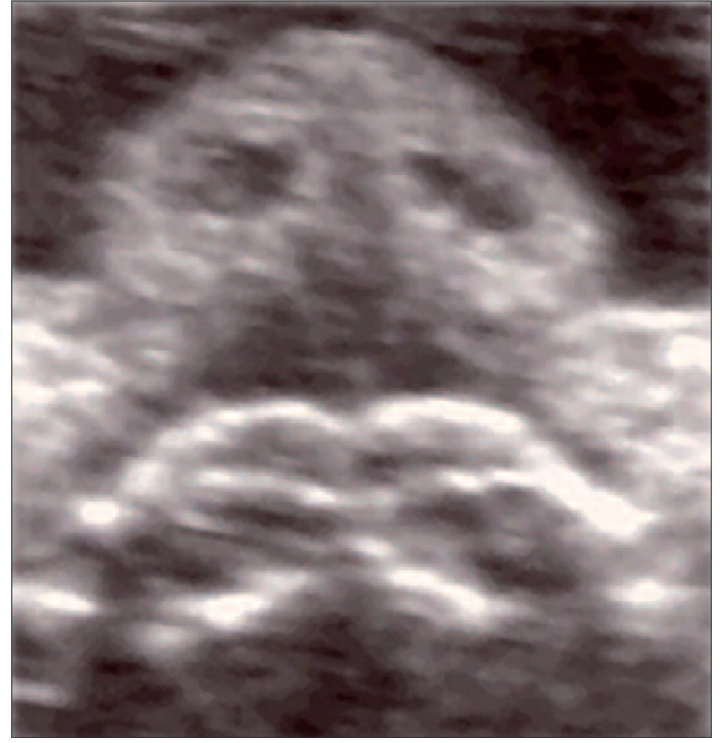

Figure 2

Ultrasound image of a 27 week fetus showing the nostrils and the developmental crypts of the maxillary central incisors (documents of Dr. Cl. Talmant) confirms the comparable transverse diameters of the nostril openings compared to those of the contents of the crypts.

crowns of the upper central incisors, and based on the enlargement of their mesio-distal diameter. This relationship lasts until the eruption of the permanent central incisors ${ }^{30}$. Conversely, somewhere between 6-9 years of age, when these crowns leave their pre-maxillary containers to make space for their roots, the development of the nostril openings can go through a critical phase when these roots are subjected to apico-transverse compression, as a possible dysfunctional nose begins a growth spurt at puberty. Is there a better example of oronasal growth function among structures that have long been considered to be solely dedicated to mastication?
Furthermore, the agenesis of one of the central incisors is yet another manifestation of and convincing evidence for oronasal morpho-physiologic integration ${ }^{57}$.

In short, the container-contents relationship of the facial envelope maintains an extremely delicate mechanics linking the transverse development of the nostril section of the pyriform aperture to that of the crowns of the upper central incisors $^{31}$. The upper lip, which is raised up by the development of the buds of these teeth, contributes to their modeling. And conjointly with this modeling, by sagittally compressing these crowns inside the pre-maxillae, the upper lip widens the nostril openings to which it is integrally connected. Rapidly, the shape then the hardness of these crowns becomes an asset for nasal functioning. The indentations (Fig. 3) that lift the vestibular face of the pre-maxilla also highlight the local morphogenetic connection in place between: - compression forces of the containers (labium superior alaeque nasi sector [upper lip and nostrils] of the facial envelope, mucosal periosteal premaxillary envelopes); - expansion forces of the developing crypt contents. During the transverse development of the nostril openings, the expansion forces of the pre-maxillary crypts pressing one against the other, and supported by amniotic breathing, forcefully widen the nostril openings, the median palatine suture, the pre-maxillae and the facial envelope. At birth, the pre-maxillary incisor-canine region has become the widest of the maxillae ${ }^{7}$. 

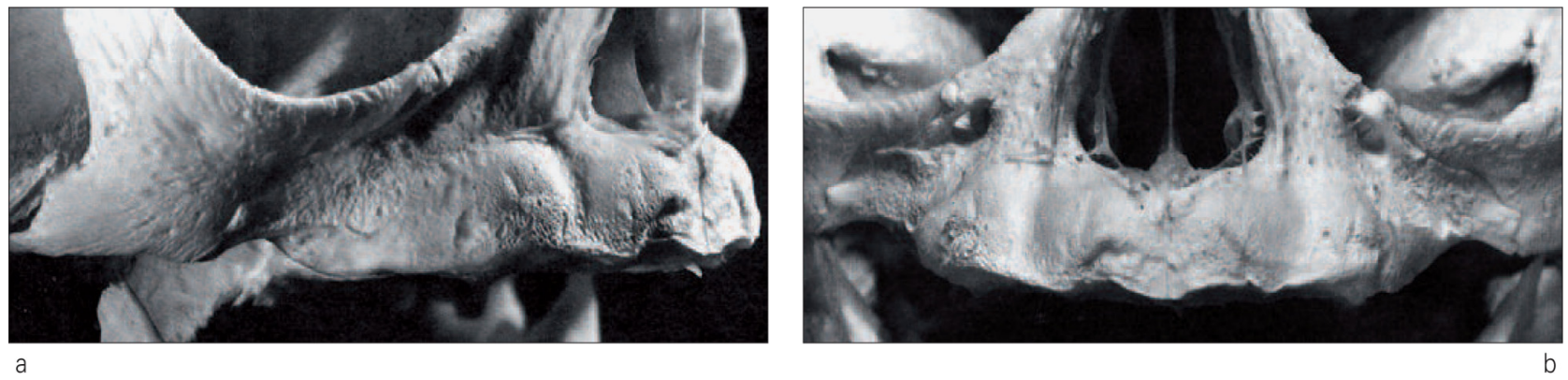

Figure $3 a$ and $3 b$

Towards the seventh month of prenatal development, these indentations show the mechanical nature of the morphological connection that operates locally between the elements of the container: the facial and pre-maxillary envelopes; and its contents: dental crowns. Only a thin bony wall separates these dental depressions from the nasal floors and the eye sockets (after van der Linder and Duterloo ${ }^{31}$ ).

\section{1 - 3 - Perspectives}

As for the development of shapes associated with the different at rest postures adopted by the facial envelope $^{56}$, it demonstrates the labium superior alaeque nasi integration of the oro-nasal structures of the envelope, which may require consistent treatment. The connection between the shapes of the nostrils and those of the upper lip accompanies the preceding mechanical relationship and in fact suggests that, after a clinical examination, this morpho-physiologic integration is at the back of the labium superior alaeque nasi position at rest: a position of simultaneous respiratory intake and nasal valve control, the only active moment of the breathing cycle of the facial envelope, even at rest, engaging all the oral nasal facial skin muscles.

Such a position results especially from the relationship of the soft tissues of the container, the facial envelope with the osteodental and cartilaginous tissues of its contents. Breathing subjects an oro-naso- pharyngeal aggregate to the dynamics of this relationship, and this complex, whose labium superior alaeque nasi, nasal and velopharyngeal soft tissues are stretched by the respiratory pressure gradient, reacts in a normal controlled manner (Fig. 4). However, signs associating labium superior alaeque nasi, pyriform and upper incisorcanine arch dysmorphisms to uncontrollable snoring vibrations of the soft palate that generate parietal and lymphoid lesions of the pharynx, appear within the context of a disturbance of this dynamic. They involve the same oro-naso-pharyngeal area, and stem from the same nasal dysfunction. The traumatic vibrations come from their transmission through the inspiratory column to the soft tissues located above the soft palate, from the tail of the lower and middle turbinates (the radiographic opacity of the turbinates demonstrates the extension of the turbinal trauma) to the nostrils. Anyone can reproduce this sound by making the soft palate vibrate while breathing deeply with the mouth closed. 


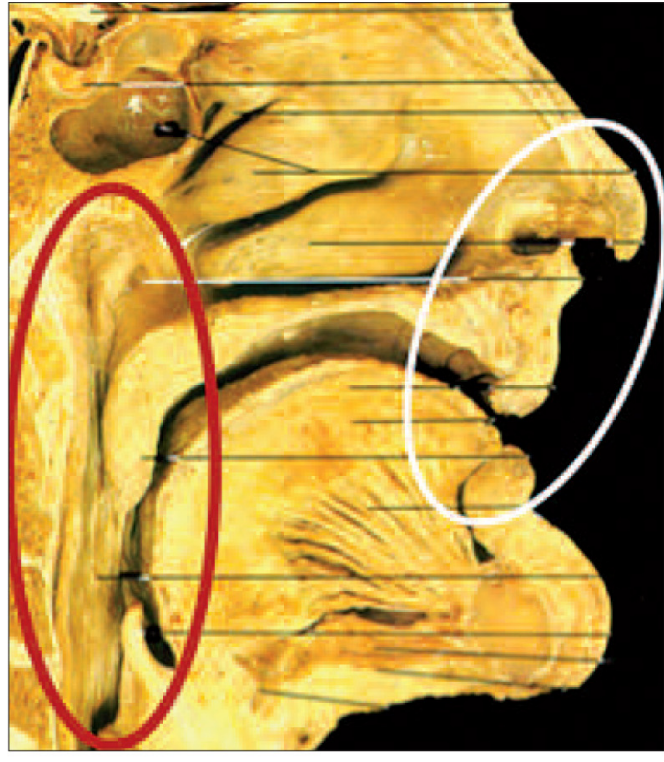

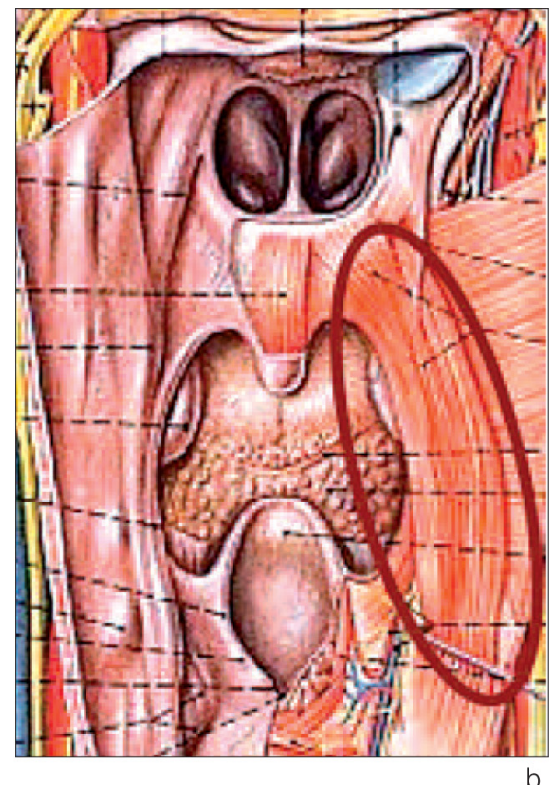

Figure $4 a$ and $4 b$

a: sagittal cut of the face. This sagittal cut (after Rohen-Yokochi46) shows the extent of the mucosa from the pharynx to the nostrils affected by the traumatic vibrations of snoring. This is not limited to the veil, pharynx and the lymphoid tissues. From the direction of the inspiratory column it extends to the lower and middle mucous-covered turbinates up to the nostrils. In suppressing the cause of snoring, one orthopedic treatment done early enough allows remission of these traumatic lesions and reduces the need for excessive surgery of hypertrophic non-cryptic tonsilar and adenoidal tissues.

b: ventral wall of the pharynx. This view of the ventral wall of the pharynx (after Sobotta ${ }^{50}$ ) shows how the palatal-pharyngeal muscle originating at the back of the veil until it is lost in the lateral wall of the pharynx. It helps explain the mechanism of transmission of pathologic snoring vibrations from the veil to the walls of the pharynx.

In this context, clinical experience shows that associated transverse maxillae-pre-maxillae and labium superior alaeque nasi deficits grow in the dorso-ventral direction and reach their maximum at the incisor-canine level. In order to effectively correct them, the orthodontist should have a sufficiently global yet cautious awareness of the anatomo-physiological relationships of the face, involving the velar, tubal, turbinate and valvular mechanics, including those of the facial and pharyngeal envelopes. Only then, will it be possible to promote the morpho-physiologic and oro-nasopharyngeal integration by performing a very simple orthopedic procedure: pre-maxillary expansion. This treatment will make it possible to begin reestablishing improved conditions for optimal breathing and growth. Until the condition of the nasal, velar and pharyngeal mucosa, whose expansion may neutralize the traumatic impact of the pathology, shows indication of healing that is most effective with early treatment. Since the noxious trauma caused by the vibrations of snoring has been amply 
documented $^{9}$, the extent of the altered mucous region must be reevaluated by including the turbinal mucosa that makes the need for orthopedic treatment of young patients even more of an imperative ${ }^{38}$.

In order to be productive, this therapy must rid patients of some very real dysfunctions that need to be identified. The physiological relationship between the turbinal mucosa and the interpositioned cavernous sinus, controlled by the autonomic nervous system (ANS), by thermoregulation of the structures of the dorsal pole of the eye and of hypothalamic-pituitary axis ${ }^{61}$ (their blood supply by the ophthalmic and pitui- tary arteries, coming from the internal carotid artery (ICA), during and after crossing over the cavernous sinus, is clear evidence of this) (Fig. 5), oro-naso-pharyngeal therapeutic perspectives necessarily become cephalic. And the practitioner, when aware of the extension of the area for which therapy can now optimally improve the physiology by using cold air from the nose, must become more attentive to the entirety of the functional complex, in which the oronasal structures are also integrated, taking into account the conditions required for effective treatment to cure presenting clinical problems, that chiefly impact sleep.

\section{2 - HOW TO APPROACH THE MECHANICS OF THE FACIAL ENVELOPE?}

We should review the definition of this envelope, and then examine it in situ and show the utmost respect for the integrity of its components and their relationships.

\section{2 - 1 - Definition of the facial envelope}

- When considering the thickness of the container formed by the aggregate of soft tissues of the covering or envelope of the facial region, going from the skin to the mucosa by way of the superficial musculoaponeurotic system $\left(\right.$ SMAS $\left.^{47}\right)$, facial muscles, alar cartilages, vasculo-nervous pedicles, subcutaneous fat... In continuity with the cranial and cervical envelopes;

- associated with its contents formed by cartilaginous and osteodental supports going from the zygo- maticomaxillary complex to the hyoid bone, by way of the lateral cartilage of the nose in continuity with the septum, the mandible and the alveolar-dental arches; makes it possible to define the most important and vital container-contents relationship for oronasal morphogenesis and oronasal physiology.

\section{2 - 2 - Case of bilateral congenital peripheral facial nerve paralysis}

Clinicians should immediately be cautious and not allow themselves to be fixated on the supposed action of the facial muscles, because this skinless model does not explain all of the biomechanics of the envelope. According to Couly ${ }^{12}$, the action of the facial skin muscles "is limited to 


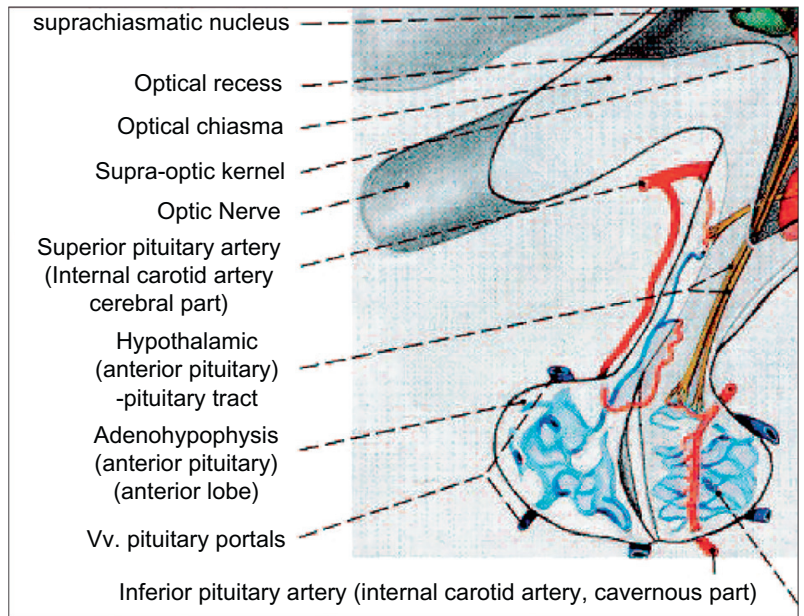

simple adjustments"' (Fig. 6). His position is based on observations of an adult patient suffering from secondary bilateral congenital peripheral facial nerve paralysis as a result of trauma to her two facial nerves during obstructed labor. The bilateral protruded arches associated with this paralysis supports his argument for the minor role that the facial muscles play in the growth of the face and related membrane bones. To account for this apparent dysmorphism however, it requires coupling labial dysfunction with that of the nasal valves along with all its postural and morphological consequences.

With the loss of active control of the oro-nostril openings of the envelope by the facial muscles, this subsequently stimulates the adaptation of the tongue and masticatory muscles to compensate. In spite of the previously mentioned dysfunctions, the osteodental and cartilaginous supports of the envelope allow it to pursue its functioning as container vis-à-vis its contents. These supports have allowed this unit of complementary parts to mold the relationship of
Figure 5

On each side, the ophthalmic artery and the pituitary arteries (superior and inferior) start at the internal carotid artery along or after it traverses the cavernous sinus (after Sobotta ${ }^{50}$ ), contributing to the physiologic relationship between the nasal mucosa and the cavernous sinus. Under the control of the autonomic nervous system, they are involved in the thermoregulation of the structures of the dorsal pole of the eye and the hypothalamic-pituitary axis.

these two members where the container, even if it had lost some finemotor skills of its facial skin muscles (VII), has nonetheless retained its muco-cutaneous sensitivity (V).

These critically important facts lead to an examination of the morphological interaction linked to the containercontents relationship, and raise the question of the role of trigeminal somesthesia in the postural behavior of the facial envelope. A problem such as this, is usually of a biomechanical nature because within the cutaneous covering of the envelope: "Some specialized nerve cells, the receptors, convert the energy associated with mechanical forces...into (biological) impulses that send data involving the stimulus to the brain. These afferent sensory messages activate central neurons that interpret the qualitative and quantitative properties of the stimulus, and in certain modalities such as somethesia...locate it in space ${ }^{41}$." Do we complain about our foot when someone hits us on the head? However, the oronasal region $\left(V_{2}, V_{3}\right)$ is different from other facial regions due to 

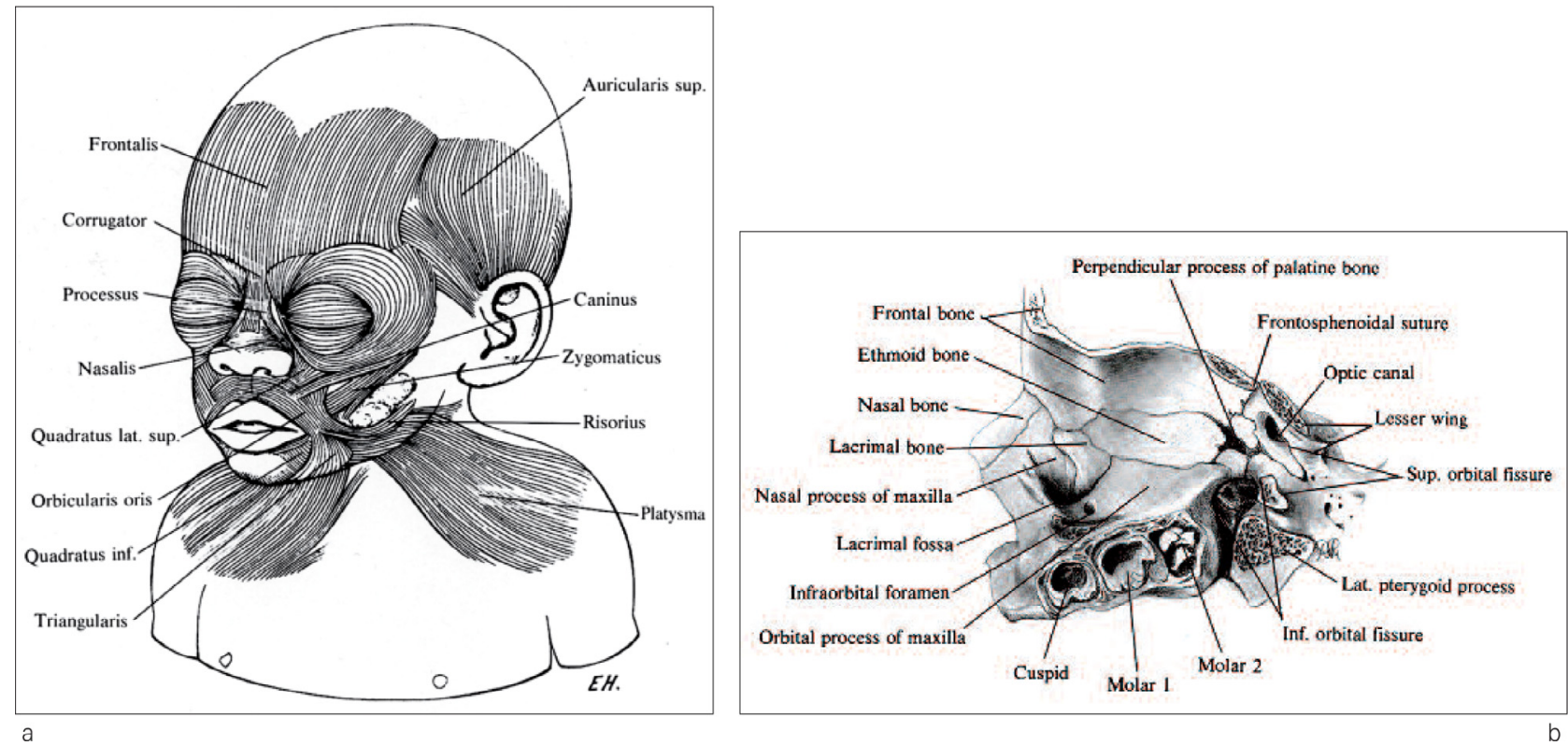

Figures $6 a$ and $6 b$

a: facial muscles of a newborn; b: profile of the orbit

Lateral view of the facial muscles of a newborn and a parasagittal cut of the orbit (after Bosma ${ }^{7}$ ). It is important to associate the facial envelope with certain characteristics of its content. The close proximity of the dental crypts, to the nostril openings and the floors of the orbits, shows where these anatomical relations differ from those that are more common. Understanding these physiological changes that accompany this development is made even more difficult because the available anatomical evolution during growth does not compensate for the lack of data concerning postnatal anatomical changes. And when we use available anatomical data to bridge this gap, we are using out-of-date analytical methods that are inconsistent with the real objective of morphogenesis, namely a reliable etiopathologic approach.

the organization of its cutaneous receptors.

Understanding the biomechanics of the facial envelope complex therefore leads to the study of phenomena relating the development of forces that appear within it to the development of the shapes that the envelope assigns them - by way of the trigeminal somatic system.

\section{3 - OVERALL MECHANICS OF THE FACIAL ENVELOPE}

"Complexity has a dimension in biology that it does not have in physics."

Jacrot B. Reductionism and complexity. In: Physics and Biology 26.

\section{3 - 1 - Growth and pre-stress}

In 1977, Solow and Kreiborg ${ }^{51}$ emphasized a feature of the overall mechanics of the envelope when they 
introduced "the hypothesis of softtissue stretching". This might explain why the relationships of craniofacial morphology are more involved with the craniocervical position than with the positioning of the head due to gravity. In fact, the facial envelope imposes a pre-stress of growth on its skeletal contents that is stronger than the force of gravity.

For Gordon ${ }^{21}$, this is an established fact: "Living tissues are always under stress. Particularly in vertebrates most soft parts are pre-stressed in one way or another: even at rest, they undergo some tension, just like the rigging of a ship." We still have to differentiate ${ }^{33}$ : - the internal stresses, forces or torques that originate within a structure undergoing a deformation (the pigskin of a football that is blown up): breathing subjects the container of the facial envelope to deformations even if they are controlled; - the applied stresses, causing a deformation (the air pressure that blows up the pigskin). By raising the facial envelope, the growth of its cartilaginous contents: nasal capsules and Meckel's cartilage, and the premaxillary development originating from the teeth, deform it and put it under pre-stress.

The evolution of the container-contents relationship operating during the morphogenesis of the shaft of the femur demonstrates these nuances. The discussion of the femur requires an update on the interpretation made by Culmann and Wolff lquoted by D'Arcy Thompson ${ }^{13}$ ) concerning the mechanisms governing the femoral bony trabeculae (Fig. 7). They are organized along the stress lines, guided by the tensions and compressions that the develop- ment of the thigh deploys within the femoral periosteum. However, this envelope comes in succession to the perichondrium, but only after the perichondrium is supplied by a pedicle composed of blood vessels and nerve and then differentiated from osteoblast involved in internal endochrondal and external periosteal ossification. As with the face, this cartilaginous proliferation might place the pre-stressed perichondrium under the control of a tegumentary envelope. Next, the action of the periosteum occurs and bone development is under periosteal control. In each case, proprioception might involve the evolution of the container-contents relationship in response to the absence of innervated cartilaginous tissue and perichondrium to the incapacity of the fetus, which is floating in amniotic fluid in a neutral hydrostatic equilibrium, to sense how much it weighs at this point ${ }^{58}$.

In 1938, Jacobs first described the growth stresses in botany ${ }^{25}$. According to Mattheck ${ }^{34}$, the circumferential pre-stress on a radial cross-section of a growing tree (Fig. 8), would operate on the periphery just as the stress of compression (or of a rubber belt) would, whereas in the center of the tree, cellular compression involves longitudinal tension. Overall, the spatial distribution of the volumes is modified during growth by integrating the tridimensional development of the stresses. Just as a cylindrical balloon does during inflation, or as the femoral diaphyseal perichondrium does whose development might be guided by the tegumentary envelope of the thigh and its contents, before its conversion into the periosteum bone. The pneumatic ${ }^{34}$ principle is a 

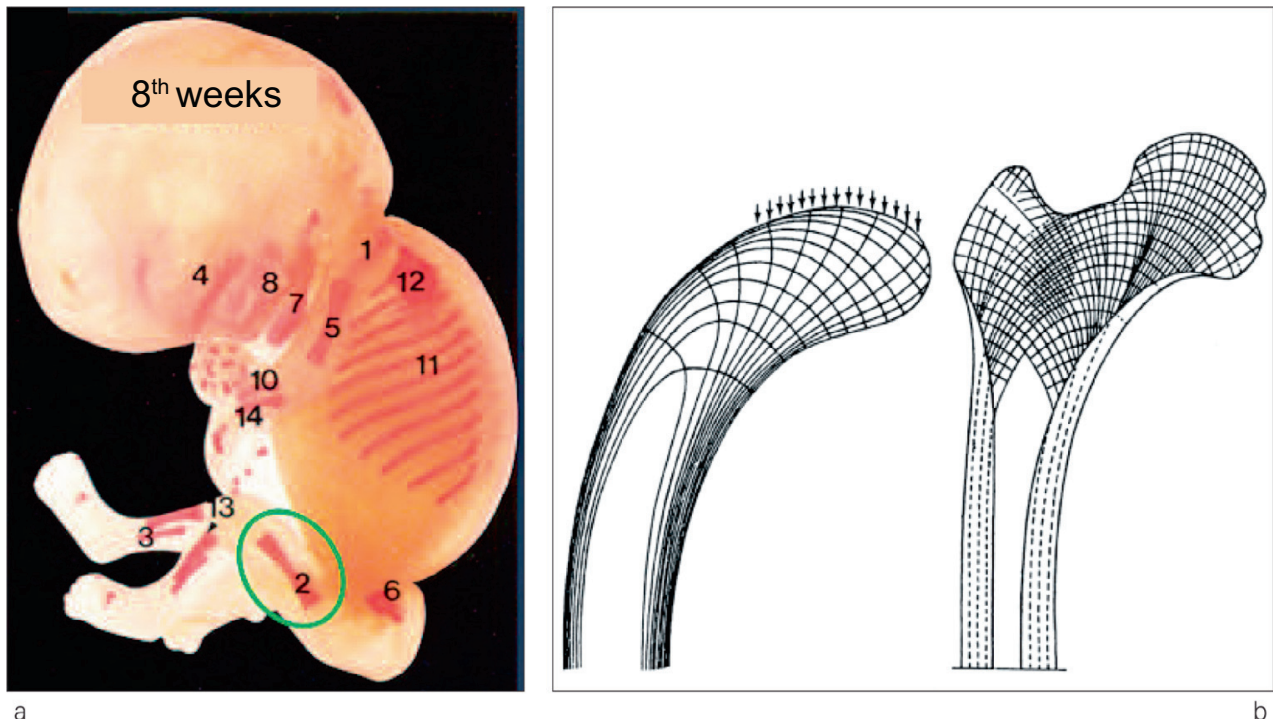

Figures $7 a$ and $7 b$

a: 8-week fetus. By the $8^{\text {th }}$ week, femoral ossification (evidenced by alizarin red dye followed by discoloration) bearing the mark of the envelopes that enclose the femoral anlage: the cutaneous envelope of the thigh and its contents whose envelope responds notably to pre-stress on the cartilaginous anlage (after England ${ }^{17}$ ).

b: adult bony trabeculae. Culmann and Wolff (after D'Arcy Thompson ${ }^{13}$ ) underscored the analogy of the organization of the stress lines within the head of a crane with that of a femur. But this analogy does not hide the continuous reorganization of the femoral bony trabeculae, in relation to the appeared constraints within the periosteal envelope and their changes during growth. The trabeculae of this schema are evidently those of an adult balance.

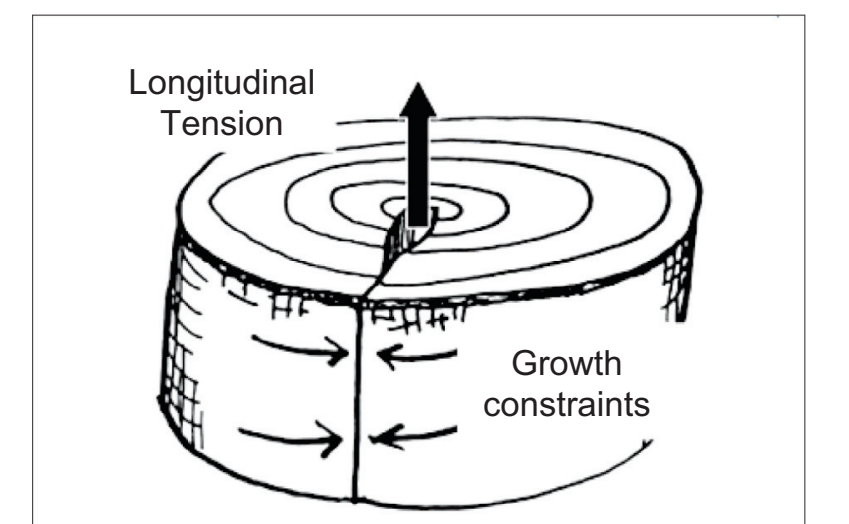

Figure 8

This schematic of a green (living) tree trunk shows how the mechanical equilibrium of the stress of growth developed within (circumferential compression and longitudinal tension), can compress the axial saw blade that axially cuts it along one of the annular rings (after Mattheck ${ }^{34}$ ).

Circumferential compression

precise application of this mechanism. The walls of car tires are strong and resistant in order to withstand and transport the heaviest of loads; they do not buckle because they are pre-stressed for tensile stresses by the pressure inside the inflated tire. Just as a blade of grass stands up after watering, once again supported by the sap that inflates it veins and 
reestablishes their pre-stressing and thus provides a good demonstration of morpho-physiology.

Subjecting the container to the expansion of its contents is one of the physical means that nature uses to ensure the pre-stressing of living tissue - starting with the cell ${ }^{52}$.

\section{$3-2$ - The role of the facial envelope as coordinator}

It is extremely important to note that the cutaneous container, all in a single unit, makes it possible for the facial envelope (Fig. 9) to mechanically coordinate the morphogenesis of the complex of its oronasal contents, just as it does for its fronto-orbital contents, even in cases of bilateral congenital facial paralysis. However, failing to understand its function as container, by disregarding the integrity of its components, and the integrity of the relationships among its components, will not make possible the perception of its postural physiology, due to the too loose anatomical dependence of facial muscles and cutaneous captors.

The container-contents complex of the facial envelope forms a single unit and the cutaneous region of the container ensures a measure of morphological coherence but not necessarily its optimal physiological coherence.

\section{3 - 3 - Form and growth}

In his seminal work, D'Arcy Thompson ${ }^{13}$ highlights an essential aspect concerning these biomechanics. Similar to inert matter, cellular and extracellular forms are subjected

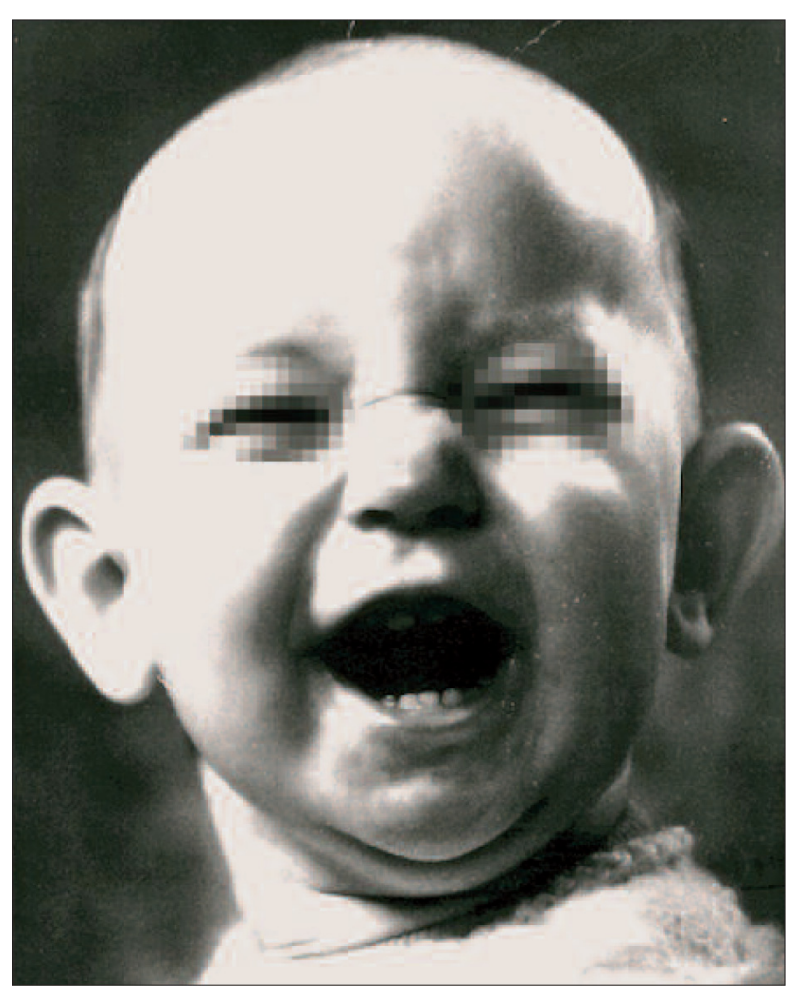

Figure 9

Its cutaneous plane, by creating a one-piece container, causes the facial envelope to be the main operator for coordinating the shapes of its supports. However, our understanding of the physiology of posture, is still an unanswered question, and requires further precision.

to "the effects of energy". By what processes? He wrote: "The problems of living matter are above all mathematical problems, and their growth problems are essentially physical problems: as a consequence, a morphologist is ipso facto a student of the physical sciences."

The effects of hydrodynamics ${ }^{58}$ are fundamentally those of a forger, because hydrodynamics does not act alone. Without imposing a shape since they are shapeless, incompressible liquids distribute some of their volume to the contents by transporting substrates used in cellular func- 
tioning. They thus allow their membranous containers to function in situ like so many flexible hydraulic jacks that they activate. Each one gives its form to each container-contents relationship by way of multiple mechanical or physico-chemical processes such as: osmotic pressure, cytoskeletons, and membrane functions... Nearby structures are in continuous interaction. Other membranes (aponeurotic layer, basal, sheath, meninges, pericardium, perichondrium, periosteum, peritoneum, pleura etc.) add other shapes when grouping several containers of the same magnitude by tissues, organs, circulatory systems, and organisms. At each level appears the shape-giving role of the membranes when surrounding the contours of their content, from the cell to the organism. And within this organization, the coupling of genetics with physics remains permanent.

However, the disproportionate number of components involved in morphogenesis, multiplies considerably the number of their interactions. Since the entirety can no longer be compared to a simple structure, a true understanding of its properties forces us to push beyond a reductionist analysis. Even for a physicist"26: "Biology is, by definition, a science which, in its totality, is a discipline filled with complexity in the richest sense of the word. In fact, life is an emergent property that exists in the cell but does not appear in any of its isolated components."

\section{- The concept of emergence}

According to Davies", "Emergence is one of the most important concepts in the study of morphogen- esis, and indeed in developmental biology as a whole." But since it is not specifically intended for any one discipline, this concept is of interest for all the sciences, from physics to biology. Laughlin ${ }^{29}$ (Nobel Prize in physics in 1998 for his work on condensed matter) states that emergence brings up a very important point: we cannot reduce physical realities that surround us to that which takes place on an infinitely small scale. The lack of physical justification for rigidity is only one example of how this idea is limited. For this author" $^{30}$, the concept of "emergence" designates a physical principle for organization: it represents laws for which we cannot deduce the existence of more fundamental physical principles. Nature is filled with objects that, by analogy, could be compared to impressionist paintings. As rendered by Monet, a field of flowers attracts our attention by presenting a "perfect" whole. The daubs of paint nonetheless are randomly shaped and imperfect. However, this imperfection of the individual brush strokes shows that the essence of the painting is its high degree of organization. What we see is of greater worth than simple splotches of paint. We can say that the painting emerges from a complex of spots that are apparently disorganized."

\section{- Biological shapes, the product of emergence}

Therefore, the appearance of a living organism is more than a simple accumulation of cells. The very essence of a biological shape is actually 
its physical principle of organization. This shape emerges from the aggregate of diversified container-contents relationships, encapsulated and hierarchized collectivities similar to Russian dolls ${ }^{4}$. Each of their levels: infra cellular, cellular, tissue, visceral, organic helps us identify the container and the contents as their morphological interactions continually ensure a function or an aggregate of specific functions, such as the cells of a blade of grass or of a tree.

For Bak1: "Complex behavior can arise from models with a simple architecture through a process of self-organization." During the morphogenesis of every complex system, consisting of organelles, cells, tissues, viscera and the organism, auto-organization represents spontaneous and dynamic emergence, of a spatial structure that did not exist prior to this in its initial components, but is now subject to the combined effects of an infusion of external energy and the interactions between the elements of the system being studied. We want to emphasize that the concept of auto-organization is not specific to biology.

Starting from the cell up to the entire organism, the containers of the lower levels will become the content of the upper level. They both will be in concert with the permanent relationship of the circulating fluids with their conduits.

\section{- Container-contents relationship}

Regardless of the scope of the container-contents relationship under consideration, the biological shape is at the interface between physics and genetics. Even if facial traits characterize the physiognomy, what is often understood as the expression of one's character or temperament according to morpho-psychology, at least incorporates the morpho-physiologic and labium superior alaeque nasi response to demands that each face must continually satisfy.

\section{4 - SPECIFICITY OF THE MUSCLES OF THE FACIAL ENVELOPE}

"A skin cell and a neuron possess the same genetic information, but the first reads it differently from the second."

Ring K. et al. ${ }^{45}$.

Changes in the form of the facial envelope of a given subject, except for those caused by morphogenesis or growth, are linked: - to the bone anchorage of its cutaneous, muscular, mucosal and cartilaginous components; - to the cranio-mandibular movements of its skeletal supports, bringing into play the masticatory muscles and posture muscles of the head and spine; - to the shapes themselves of the facial orifices, oral fissure and nostrils in particular, and to the operational command that controls their deformations, passively by their cartilaginous framework and actively by the facial muscles.

Nonetheless, for a patient with no malocclusion, the voluntary control of 


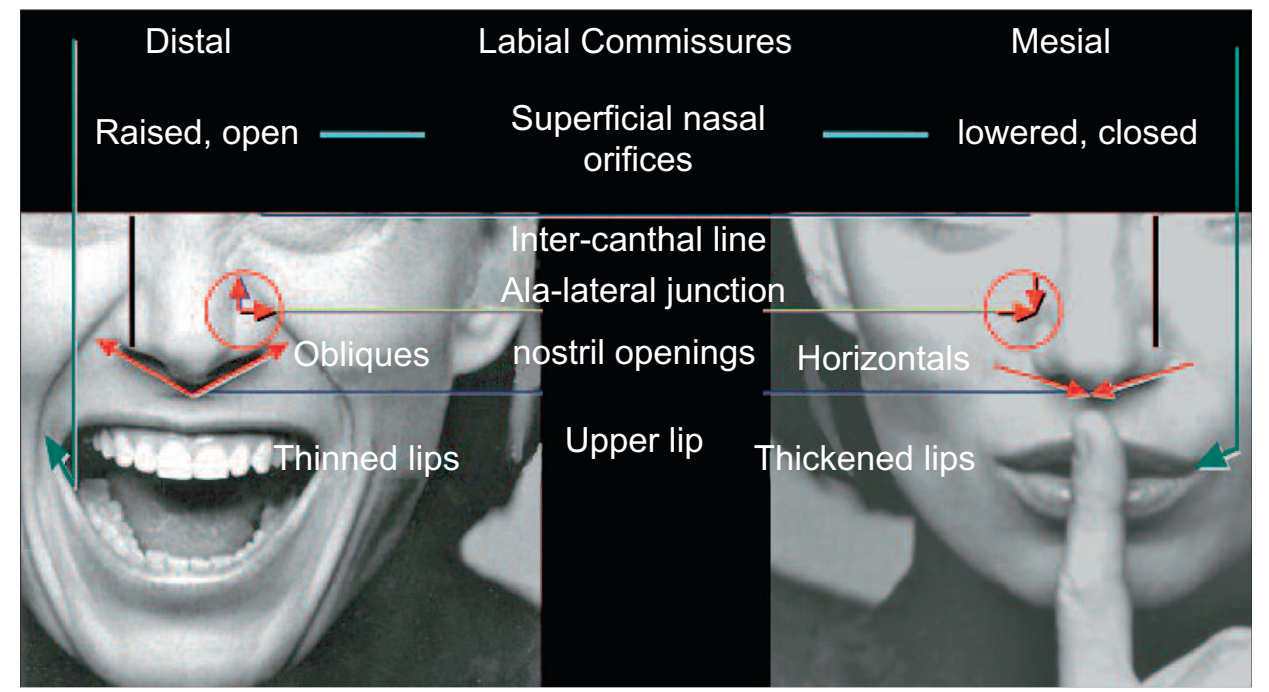

Figure 10

The voluntary dominance of the oronostril (ventral) or buccal (lateral) facial muscles, confirms an important point: the morphological interdependence of the oral fissure and the nostrils ladvertisement documents). the facial muscles both oronostril (ventral) or jugal (lateral), confirms something essential: the morphological interdependence of the oral fissure and the nostrils. Depending upon the sectorial control of the facial muscles, facial features draw closer while lowering or widen while rising, in relation to the median anchorage of these orifices (Fig. 10).

\section{4 - 1 - Absence of neuromuscular spindles}

The interdependence of the shapes stems from two characteristics of the components of this envelope: - the continuity of its cutaneous building block that remains in one piece despite the local discontinuities of its orifices; - and the specificity that the facial muscles share with the musculature of the tongue ${ }^{12}$ (Fig. 11). Unlike the skeletal muscles, no study has shown the presence of neuromuscular spindles here ${ }^{10}$, i.e. receptors that are sensitive to stretching. Until recently, questions concerning the modalities of proprioceptive information of these muscles remained unanswered.

However, the answer lies in the tight adherences of the alar cartilage and of the peri-oral facial muscles to their peri-oral, cutaneous and/or mucosal coverings. First, they associate the activity of the oronasal facial muscles with changes in the labial superior alaeque nasi, labial mental and buccinator shapes that these muscles animate. Second these adherences associate these changes with the tridimensional stimulations of the mechanoreceptors of their coverings (the corpuscles of Ruffini ${ }^{41}$ in particular, that are sensitive to stretching) that result from this. Then, the topography of this adherence brings together all the necessary elements for proprioceptive sensitivity $^{41}$. This sensitivity makes the perception of sensations relative to movements and to the position ${ }^{3}$ of the peri-oral structures: the oral fissure and nostrils. 


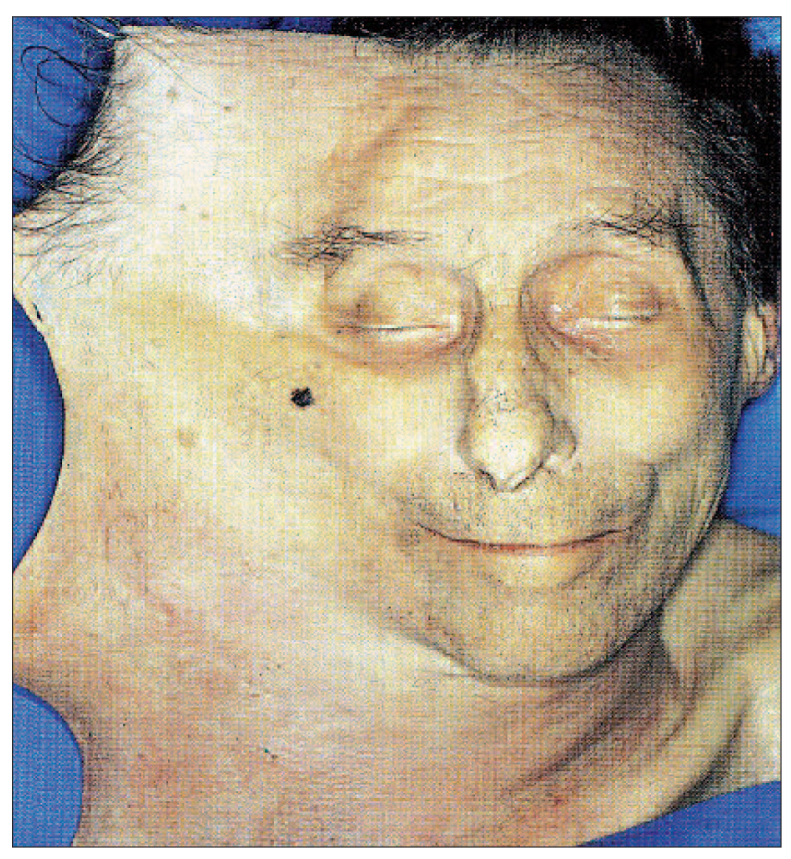

Figure 11

This document aims to illustrate the adherence of the alar cartilages to the skin, and of the peri-oral muscles to their cutaneous covering (after Saban ${ }^{47}$ ). These adherences give to the assembly a proprioceptive quality. Information received from the mechanoreceptors of their coverings permits the adhered facial muscles to directly control the spatial relationship of this complex including the nostrils. The genial skin muscles intervene directly in the spatial relationship of the oronostril region and indirectly in the spatial relationship of the cheeks.

\section{4 - 2 - Adherences of the $\mathrm{m}$. orbicularis oris and m. mentalis}

Local anesthesia of the Inferior Alveolar Nerve, unilaterally suppresses the cutaneous and the labial mental mucosa afferent sensitivities $\left(V_{3}\right)$. It also suppresses unilaterally the motor response $\left(\mathrm{VII}_{\text {inf }}\right)$ of the orbicularis oris of the inferior lip and of the corresponding chin muscles, involving a loss of a local hermetic seal during swallowing. This paresis results from a lack of information coming from the cutaneo-mucosal sensory receptors that the very strong adherence of the inferior labial coverings to the orbicularis and the chin muscle bring to the nervous system.

In normal conditions, adherence such as this influences the local shapes in different ways depending on the particular muscle. On each side, the cutaneo-mucosal covering (Fig. 12):

- Tangential to the fibers of the $m$. orbicularis oris to which its labium superior alaeque nasi and labial mental areas adhere, communicates through its receptors: directly with the orbicularis muscles, due to the pressure associated with the intercommissural stretching $(P=F / S)$, and the superior orbicularis from the corresponding air flow; - indirectly, with the genial skin muscles due to the pressure linked to their stretching between the nasolabial sulcus. The orbicularis and the mentalis medially, the genial skin muscles laterally, therefore receive their signals from the same labial, genial and nostril afferences, but work against one another while adapting to the cartilaginous and cutaneo-mucosal ventral shapes, given their adherences, their sagittal reference points and some aero, alveolodental and skeletal supports.

- Normal to the fibers of the $\mathrm{m}$. mentalis on the inferior and paramedial portion of the labial mental sector makes it possible for this muscle to raise the medial part of the lower lip by stretching and pressing the cutaneous chin 


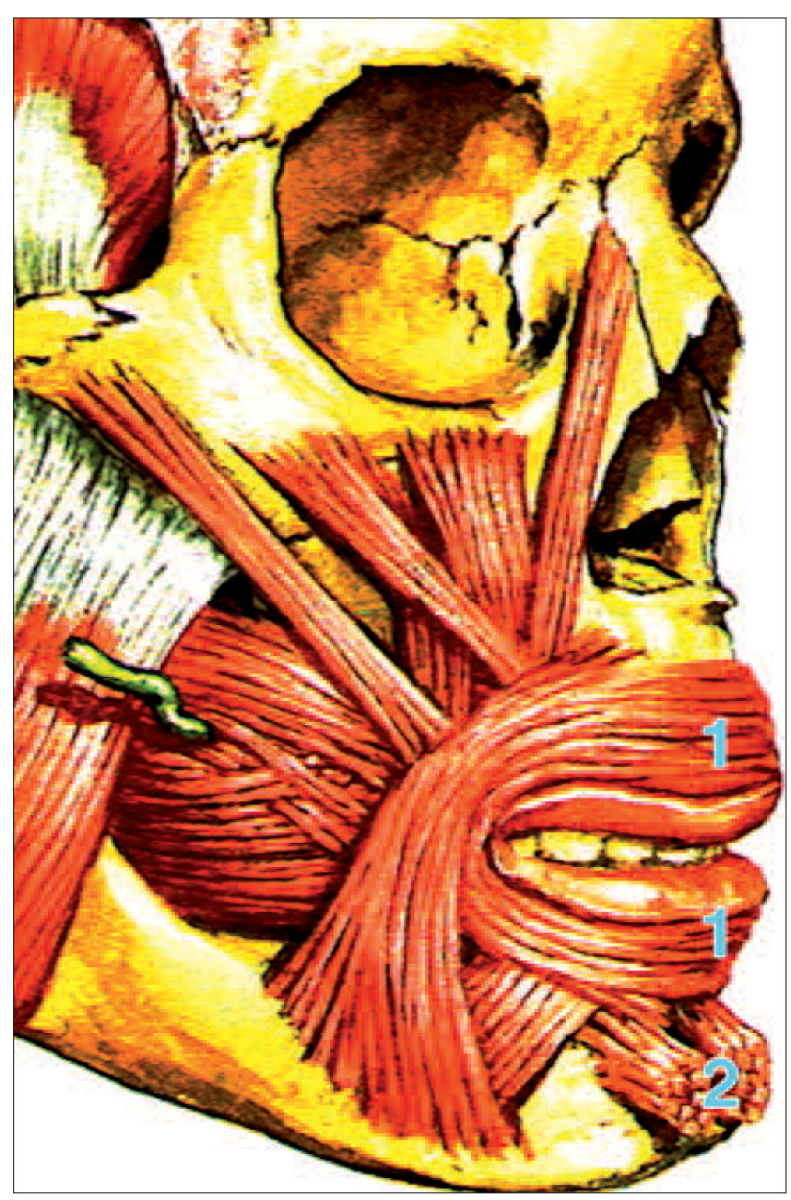

Figure 12

On each side, the influences of the facial muscles 11: the orbicularis muscles of the lips; 2: the mentalis) on the local shape of the facial envelope differ in accordance to whether the facial muscles are tangential or normal to the cutaneo-mucosal surface (after Netter ${ }^{37}$ ).

against the underlying osseous plane, starting from the submentalis furrow (Fig. 13). Therefore, the anterior part of the mouth is securely sealed (lips) during swallowing due to commissural complementary action involving the crossing of orbiculobuccinator fibers.

This operation integrates the dentoalveolar and mentalis support of the lower lip - a contrario a toothless person presents the opposite effect. It is important to point out that the submentalis furrow, transversally inscribed between lateral and caudal limits of the labial mental part of the ventral sector of the envelope, under the mentalis tubercules, indicates by this a very robust adherence to the basal mentalis periosteum: - by the superficial musculo-aponeurotic system; - by the platysma (facial muscle of the neck); - by the $\operatorname{skin}^{43}$. Mechanically, this mandibular anchorage of the envelope is crucial. It is essential for the three-dimensional positioning of the ventral extremity of the mandible, and rests on the line of separation between the axial labial mental and suprahyoid sagittal stresses; its role is important for the efficient operation of the simultaneous movements of lower lip elevation and lingual and hyoid ascension during swallowing.

\section{4 - 3 - Adherences of the alar cartilages}

On each side, a similar phenomenon appears after anesthetizing the superficial and deep (V2) coverings of the alar cartilage: the patient then experiences some breathing difficulty with a loss of perception of nasal airflow ${ }^{20}$, indicating the incapacity of superior orbicularis oris and of the genial muscles to control the compliance of the nasal valve. Once again, paresthesia reveals the lack of information that, coming from the adherent coverings of the alar cartilage, translates the passage of air flow: paced by breathing, these signals are directed to the facial muscles of the skin. 

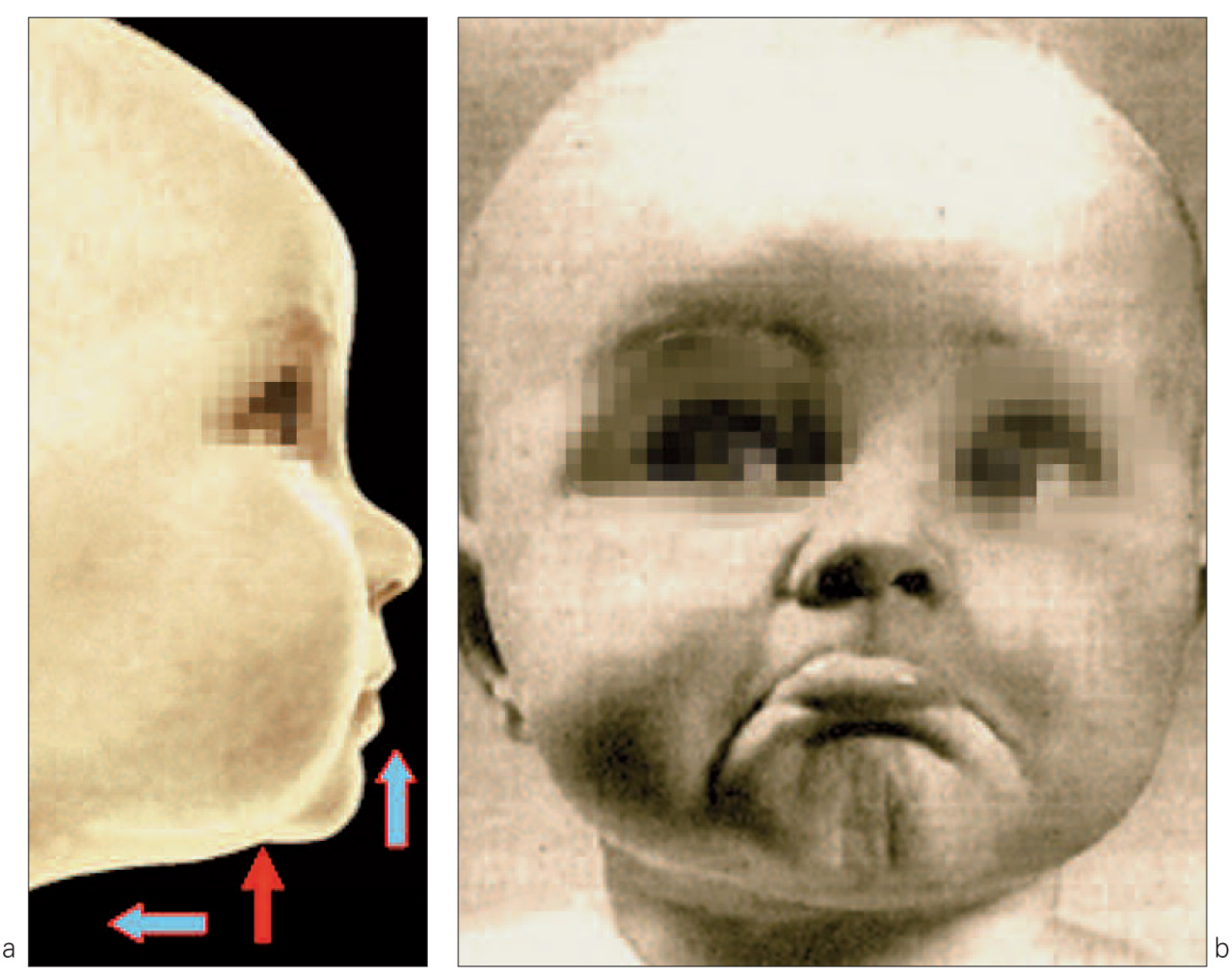

Figures 13a and $13 b$ a: profile of a nursing infant; b: infant face as a result of anchorage of the mentalis on the facial envelope.

Mandible anchorage setting of the facial envelope and the SMAS, the submental furrow is essential to the linkage of the facial envelope with the cranial-mandible posture and the postural adjustment of the anterior facial height, whatever the facial typology.
It is interesting to note that, on each side, the strong cutaneous adherence to the alar cartilage, and not to the lateral cartilage of the nose or genial facial muscles, exposes the lateral cartilage to inspiratory collapse. Stabilizing the lateral alar junction near the nasal valve relies on: - tension of the envelope linked to cranial-mandible posture; - joined with the inspiratory activity of the facial muscles. This aggregate supports the individual functional modalities ${ }^{24}$ (Fig. 14). For a patient with a dolichofacial typology, the low mandible position associated with the oronostrll vertical excess and axial stiffening of the commissural pillars (cf. infra), produces an almost vertical alar posture with pinched nostrils, and an ovoid or even gothic maxillary incisor-canine arc. For a patient with a brachyfacial typology, the sagittal mandible posture together with the buccal dominance transversely stiffening the commissural pillars, contributes to the horizontal posture of the alar cartilages with flaring of the nostrils, and an ellipsoid or even upsiloid maxillary incisor-canine arc. In both cases, the way the maxillary incisor-canine arc conforms to the labium superior alaeque nasi posture clinically shows evidence of oronasal integration.

\section{4 - 4 - Mucosal adherence on the buccinators}

On each side of the face, replicated and identical muscle adheres to the lateral surface of the buccal mucosa: the buccinator (Fig. 15). It is attached to the orbicularis oris and 


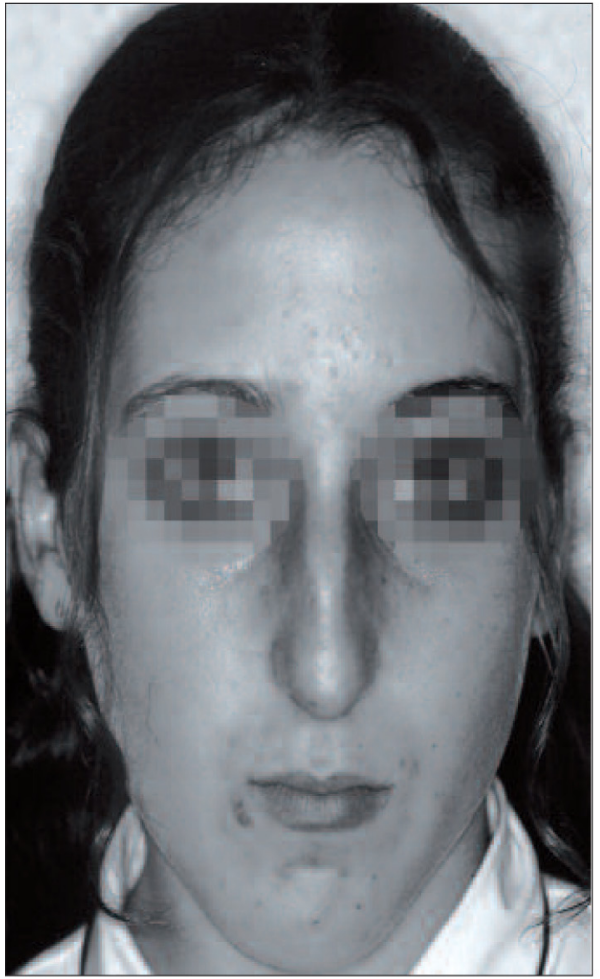

a

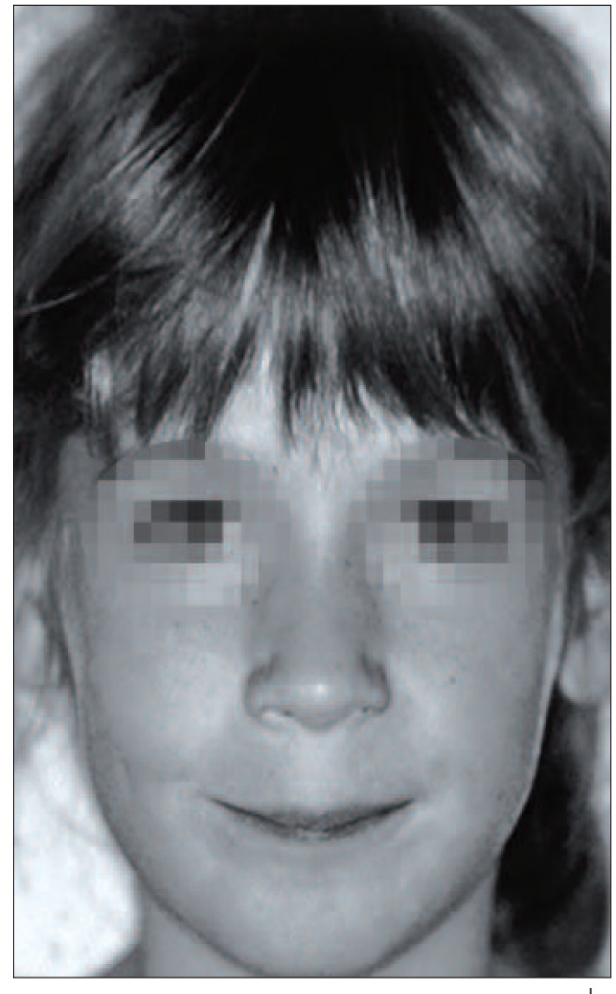

b
Figures $14 a$ and $14 b$ a: dolichofacial typology In an anterior long face, the low mandible posture and the axial stiffening of the commissural pillars, together with the oral nostril dominance, are associated with an almost vertical alae nasi posture, pinched nostrils and an ovoid or even gothic maxillary incisor-canine arc. b: brachyfacial typology In an anterior short face, the sagittal mandible posture together with the buccal dominance stiffening transversely the commissural pillars, contributes to the horizontal posture of the alae nasi cartilages with flaring of the nostrils, and an ellipsoid or even upsiloid maxillary incisor-canine arc.

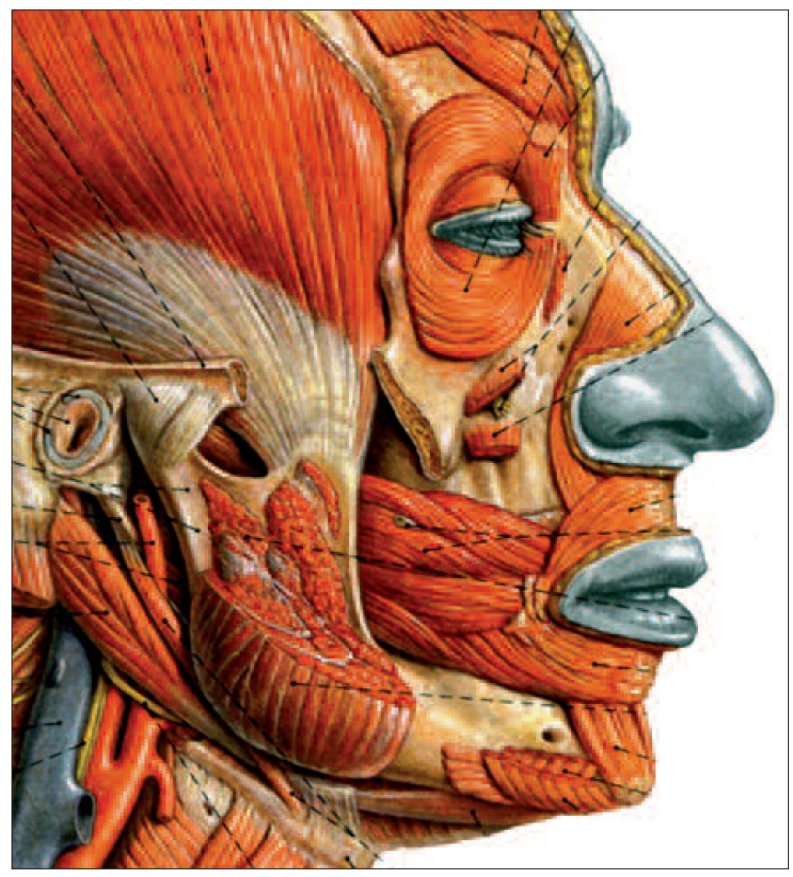

\section{Figure 15}

From each side, the ventral continuity of the $m$. buccinator, the deep muscle of the cheek, with the $m$. orbicularis oris permits it to act on the transverse dimension of the nostril openings, in view of the adhesion of the $m$. orbicularis oris to the coverings of the upper lip and the nostrils (after Sobotta ${ }^{46}$ ). 
passes through the inside of the modiolus $^{40}$. The buccal branches of the facial nerve supply it. It is continuous with the orbicularis oris (and is antagonistic to it) and laterally closes the oral cavity. Additionally, the upper lip skin is continuous with the alar coverings, and importantly this continuity extends the action of the buccinators to the nostrils. This action spreads the nasolabial sulcus and the commissures of the lips, narrows the nostril wings and stabilizes the nasal valve (especially in cases of Class $\mathrm{II}_{2}$ ). The action indicates oral nostril morpho-physiologic integration: an insufficient maxillary inter-canine diameter associated with a valve pinching confirms it.

The information coming from the receptors of the buccal mucosa, carried by the buccal roots of $V_{2}$ and $V_{3}$, helps to circulate the salivary bolus, to swallow and to avoid biting the cheeks.

\section{4 - 5 - Adherences and proprioception}

In short, between the two nasolabial sulcus, the adherences of the cutaneous component of the facial envelope to the facial muscles of the skin secure the nostrils to a complex comprising the $\mathrm{m}$. orbicularis oris, the $\mathrm{m}$. buccinators, the coverings that are adherent to them, and sustained mainly by the whole buccal perimeter of the alveolar-dental arches.

These coverings constantly relay information that is the source of proprioception of facial skin muscles. The same information is also provided to the genial muscles (Fig. 16),

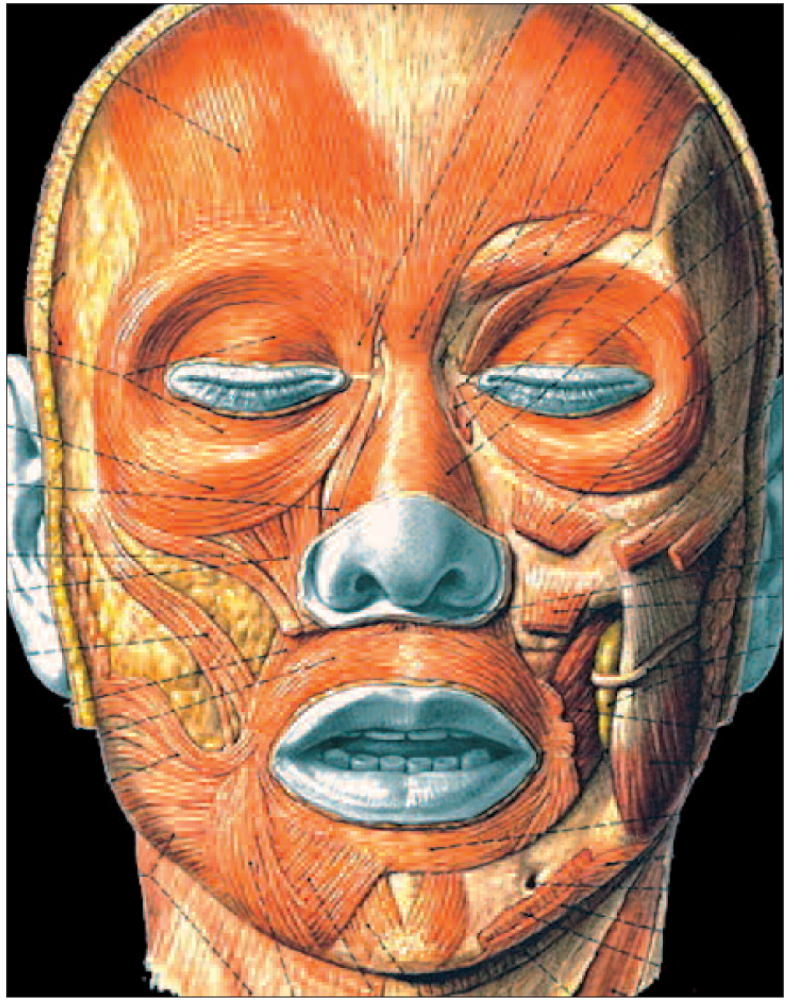

Figure 16

Their adhesion to the buccolabial mucosa closer to the vestibular aspect of the dentoalveolar arches separates the medial facial muscles from the genial ones. These are more directly specialized in controlling the nasal valves and in the postural positioning of the nasal orifices and of the oral fissure (after Sobotta ${ }^{50}$ ).

to help coordinate the motor response of the envelope to each inspiratory stimulation detected by the ventral sector:

- labium superior alaeque nasi capture of air near the superficial nostril openings and/or oral capture by controlling bilabial contact or labial opening;

- controlling or not of the lateralalar junctions near the nasal valves.

By molding their supports beginning with amniotic ventilation, the labium superior alaeque nasi and labial 
mental structures shape the ventral part of the envelope, at the intersection of the sagittal buccopharyngeal system and its lateral jugal sectors. The contributions of this complex to breathing profoundly influence their rest postures, whether or not they cause sectorial control depending on the nasal difficulties that are encountered.

However, the skin of the lips is, along with that of the hands, the area where the density of the receptors is highest; the surface of a "homunculus" (Fig. 17) shows that the sensory cortex for these areas is disproportionately large in relation to that of other cutaneous zones ${ }^{39}$. This explains the fine motor tridimensional control, by the aggregate of the oro-nasal facial muscles, of superficial shapes of the labium superior alaeque nasi and labial mental regions of the facial envelope, given its alar and dento-skeletal supports. Through its mechanism, this control is comparable to the control that the genioglossal muscles exercise over the mucosa of the base of the tongue to which they adhere, in response to activation of its receptors by inspiratory intake. Similar to the facial skin muscles, the lingual muscles are not equipped with neuromuscular bundles, but their adherence to the lingual mucosa makes them react to changes in pressure received by the mechanoreceptors of the posterior third of the tongue surface. Thus, the integration of inspiratory muscular activity contributes to optimizing nostril and/or oral capture, and when air passes through the oropharynx, given the three-dimensional perception that the adherence of the cutaneous and/or mucous coverings provide to their respective muscles.

The labium superior alaeque nasi (nostrils + upper lip) complex constitutes a sensory-motor substage of the facial envelope, innervated by the $\mathrm{V}_{2}$ and the $\mathrm{VII}_{\text {sup. }}$. Raised by the septum nasi and secured to the pyriform aperture, it provides access to the oral and nasal cavities. It is essential for nasal and/or oral capture of inspired air, and to the control of the lateral-alar junctions, engaging the upper lip in either case. While the la-
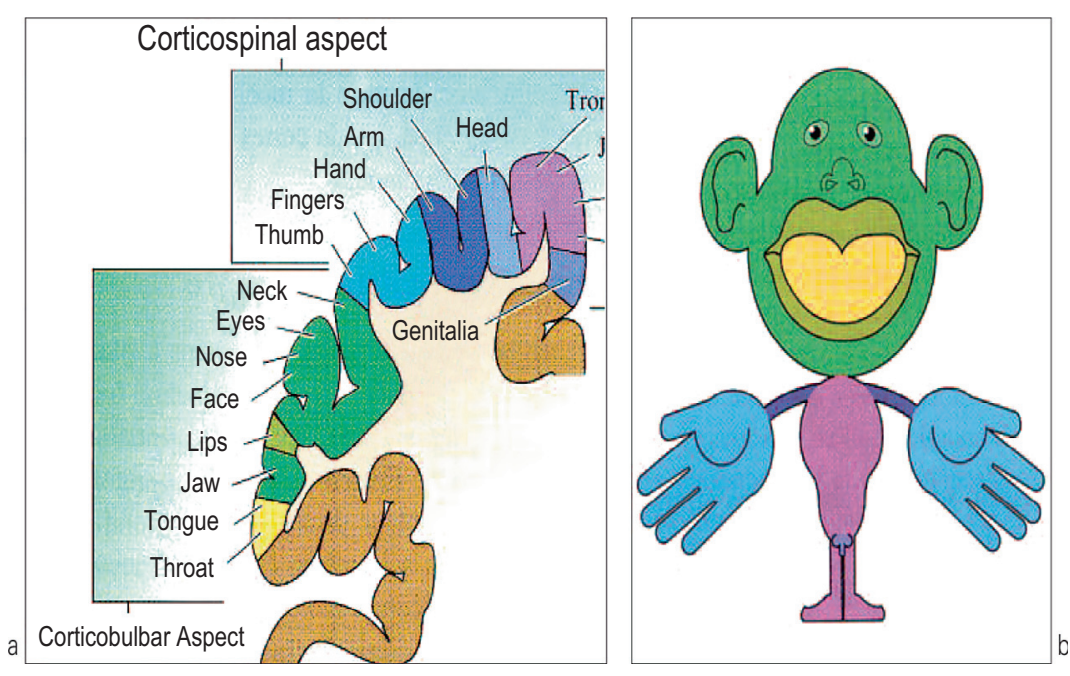

Figure $17 a$ and $17 b$

a: Somatic representation of the parts of the body controlled by the median to the lateral of the hemispheres of the brain (after Purves ${ }^{41}$ ).

(In the Diagram: Corticospinal aspect $b$ : Homonculus based on the preceding graphic (after Purves ${ }^{41}$ ). 
bial mental (lower lip + chin) complex constitutes another sensory-motor substage of the envelope innervated by the $V_{3}$ and the $\mathrm{VII}_{\text {inf; }}$ it is especially active during swallowing and phonation (accompanying the mandible when the mouth is open).

For Changeux 8 , "In biology, the explanation goes hand in hand with the identification of the structure that underlies the function and determines it." In the context of the mechanical organization of the facial envelope, the identification of the labium superior alaeque nasi sensory motor substage of its container and of the pre-maxillary, incisor-canine and alar supports of its contents, underlying the capture of intake air, can let us precisely indicate the development and the modalities of the spatial and local adjustments that trigger its physiological operation.

\section{5 - MECHANICAL ORGANIZATION OF THE FACIAL ENVELOPE}

"...For any author of a work on form, the final expression of the growth process of organisms...must take on the phenomena that demonstrate, stricto sensu, a real adaptation: an obvious mechanical aptitude of the implementation of a function..."

D'Arcy Thompson W. On growth and form. Cambridge Univ. Press $1961^{13}$.

\section{5 - 1 - Role of the concentration of stress}

Among the evidences of the role of the distribution of stress appearing within the facial envelope in the organization of its facial skin muscles, are the following examples:

- the distribution of the pre-stress of the envelope due to the development of its contents that raises it while deforming it (we've already discussed this);

- its concentrations of stress related to local variations of the geometry of the matter under stress that it is made of, and that weakens its structure $^{21}$ to varying degrees. This phenomenon gives the complex the appearance of a system that self-organizes as a result of its own dynamics ${ }^{16}$.

In the science of materials, theory and experiments show that:

- geometric singularities within a material: holes, notches, and cracks;

- concentrated loads at certain points in the material due to an anchorage, ridge, crest, a relief;

- in general, the stark variations of the shape of the surface of this material; frequently results in significant local stress that is quickly nullified by moving away from the singularity or the external load.

The case of the pre-stressed facial envelope in fact confirms that (Fig. 18):

- orifices, oral fissure and nostril openings of its oronasal and ventral area;

- the reliefs that raise this region: the nasal septum and the nostrils, the pre-maxillae and their contents, 


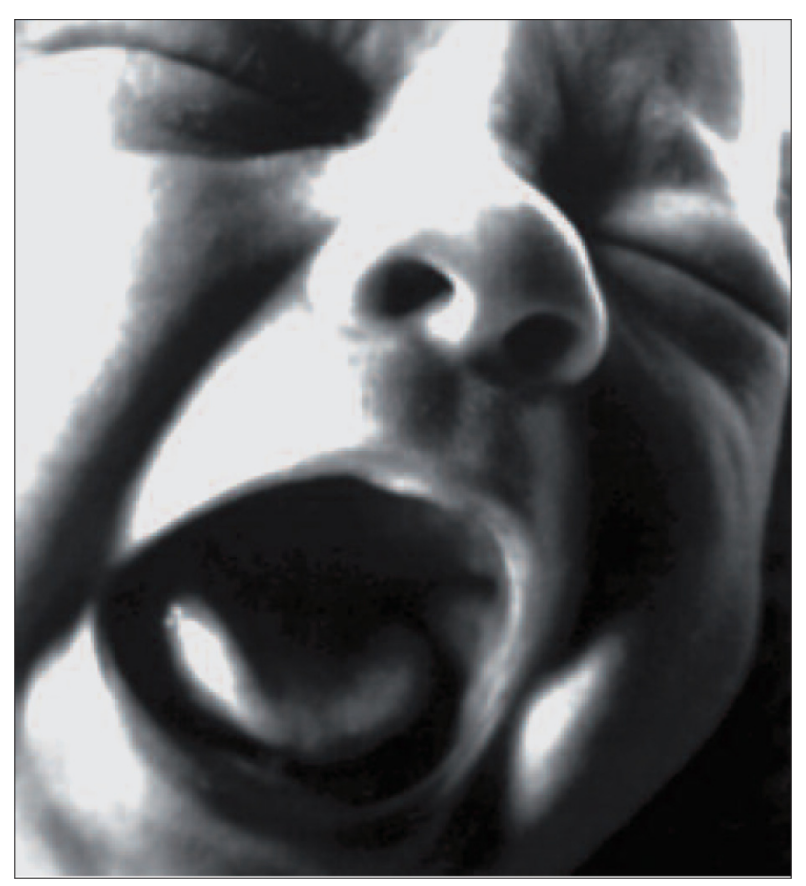

Figure 18

The facial envelope of an infant is the place of numerous pre-stresses created by the geometric singularities of its container, by the concentrations of stress caused by the contents which support it, by the stark variation of its geometry and by the deformations tied to the development of its contents.

Meckel's cartilage and the chin; are the causes of these defining concentrations of stress for its local organizational structure, where we see a permanent coupling of physics and genetics. The stress designates the mechanical aspect of this phenomenon whereas the deformations, which are always linked to it, represent the geometrical aspect of it.

\section{5 - 2 - Mechanics of the oral fissure}

Cook and Gordon ${ }^{21}$ have created a model of the distribution of the stress created near on of the extre- mities of the main axis of an elliptical horizontal slit (similar to an oral fissure) that pierces the center of a flexible rubber rod and is subjected to vertical traction. The oral fissure, by interrupting the transmission of frontal stress (vertical between the lips, and transverse between their commissures), works mechanically like an operational command. It influences the distribution and the intensity of stress near the lips and close to the commissures, as illustrated by Cook and Gordon's model (Fig. 19).

\section{- Concentration of stress - significance of the modiolus}

The diagrams of stress highlight, on each side:

- A concentration of perpendicular stress on the main axis of the fissure, located on its commissural extremity. This concentration of axial stress weakens the labial commissures. The pain experienced in the angular stomatitis (commonly called split lip) results from this mechanics;

- A concentration of stress parallel to the main axis of the fissure, located on this axis, at a distance from and lateral to the commissure.

The horizontal direction of the oral fissure could then cause:

- The positioning of the modiolus on the main axis of the fissure, lateral to each labial commissure;

- The crossing of the fibers of the buccinators.

The jugal morphogenesis in fact manifests other repercussions of these mechanics, and these after effects validate our interpretation of the data. 


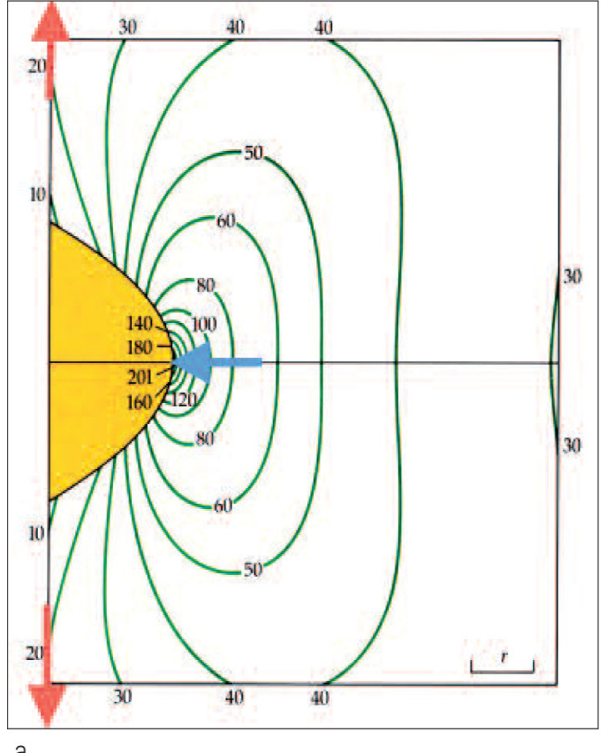

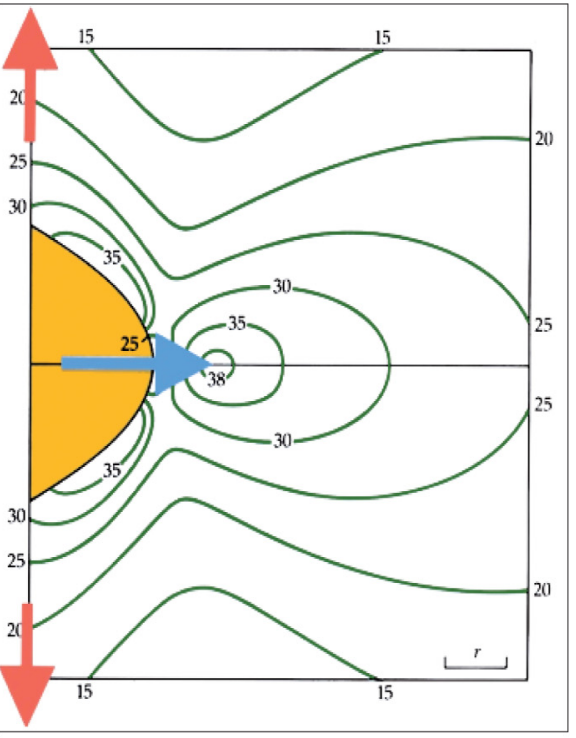

b

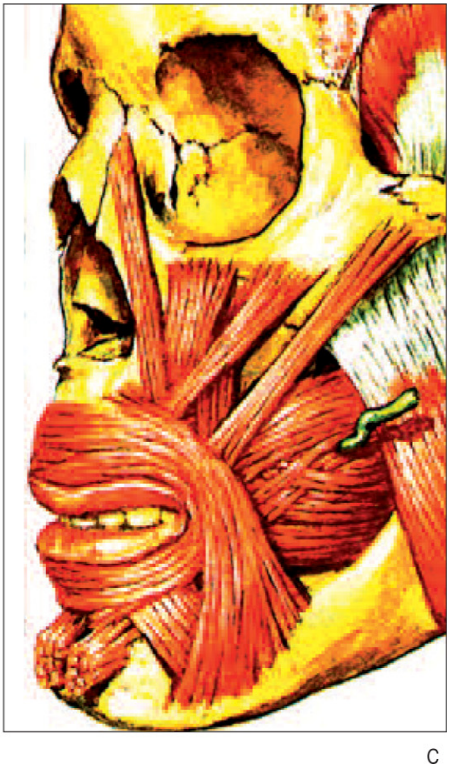

Figures $19 a$ to $19 c$

a: vertical stress

b. horizontal stress

c. facial skin muscles

These diagrams of stress (after Gordon ${ }^{21}$ ) juxtaposed to the facial skin muscles (after Netter ${ }^{37}$ ) demonstrate the disparity of concentrations of vertical or horizontal stress, caused by an elliptical horizontal fissure, that pierces the center of a flexible rubber plate subjected to vertical traction.

The diagrams reveal the mechanical significance of the trajectories followed by the fibers of the facial skin muscles, as well as of the mechanical significance of the presence and placement of the modiolus.

Despite the importance attributed to physics for explaining the structural organization of the facial envelope, we should not forget that physics supposes a permanent linkage of its action with genetics within the pre-stressed facial envelope (after Farge ${ }^{19}$ ).

\section{5 - 3 - Jugal mechanics}

During the development of the stomadeum (Fig. 20), the oronasal morpho-physiologic integration becomes apparent:

- Medially by the fusion of the facial buds that most notably trigger the formation of the nostrils and the upper lip, and during the fetal $8^{\text {th }}$ and $9^{\text {th }}$ weeks, when the inferior edge of the nasal septum meets the fused medial edges of the palatal processes aided by the myogenic mesenchymal cells destined for the soft palate.

- Laterally by the jugal morphogenesis, connected to that of the ventral sector of the envelope, the junction being indicated externally on each side by a groove, the nasolabial sulcus. This sulcus runs downside and laterally from the side of the nose (at the lateral-alar junction) to the level and lateral to the angle of the mouth. The lateral sector of the facial envelope extends from the nasal ridge to the 


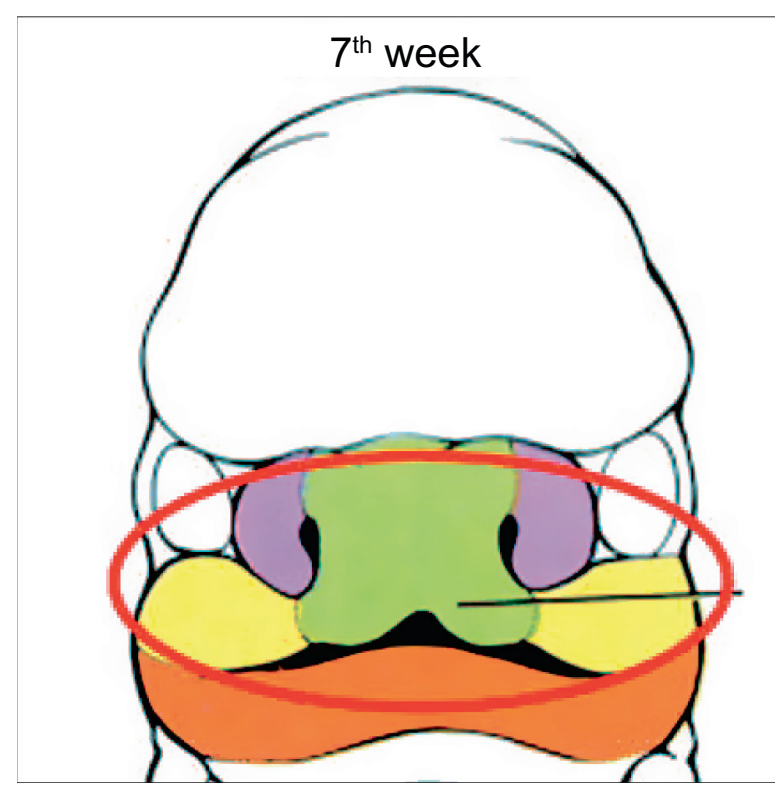

Figure 20

The fusion of the facial buds, which leads to the formation of the nostrils and the upper lip, clearly shows the compact and complex nature of the structures underlying the sensory-motor labium superior alaeque nasi system (after Larsen $^{28)}$.

$7^{\text {th }}$ week

lateral extremity of the sub-mental furrow, and downside to the hyoid bone.

\section{- Origin of the cleavage of the cheek}

According to Gordon ${ }^{21}$, on the inside of a split blade, "if the material includes planes of least resistance either obliquely or perpendicularly to the plane of the fissure, the appearance in these planes of a secondary fissure helps to block the primary fissure." However, the coverings of the axial direction that border each lateral wall of the stomadeum are subjected to stresses capable of fostering the appearance of such a split between (Fig. 1): the superficial ectoblastic cov- ering as a continuation of the tegument envelope, and the entoblastic underlying covering as a continuation of the underlying envelope of the pharyngeal intestine. And Meckel's cartilage appears between these two coverings during the $7^{\text {th }}$ fetal week ${ }^{28}$.

The retro commissural and axial cleavage on each jugal sector of the envelope might be a response to the mechanical risk created by the horizontal oral fissure. In fact, the cleavage reinforces the resistance of the commissures due to axial traction created by blocking the fissure at the intersection of the trajectories of the muscular fibers going from the cheeks to the lips. On each side, the continuity of fibers descending from the $m$. buccinator (deep) and of the $\mathrm{m}$. levator anguli oris (superficial) with those of the $\mathrm{m}$. incisivus inferior, or that of the rising fibers of the $m$. buccinator (deep) and of the $m$. depressor anguli oris (superficial) with those of the $m$. incisivus superior, demonstrate this ${ }^{62}$ (Fig. 21). According to Gordon"1, "the planes of cleavage exist systematically in wood, and the bones; they are also very common in soft tissues la steak is a good example)." The facial envelope is another example: on each side, the introduction of the plane of jugal cleavage is governed by mechanics induced by the oral fissure, that very effectively protects each commissure of the lips of mouth.

\section{5 - 4 - The mechanical partition of the facial envelope}

In the early embryo starting at the $7^{\text {th }}$ fetal week, the oral fissure and the reliefs that raise the nasal 


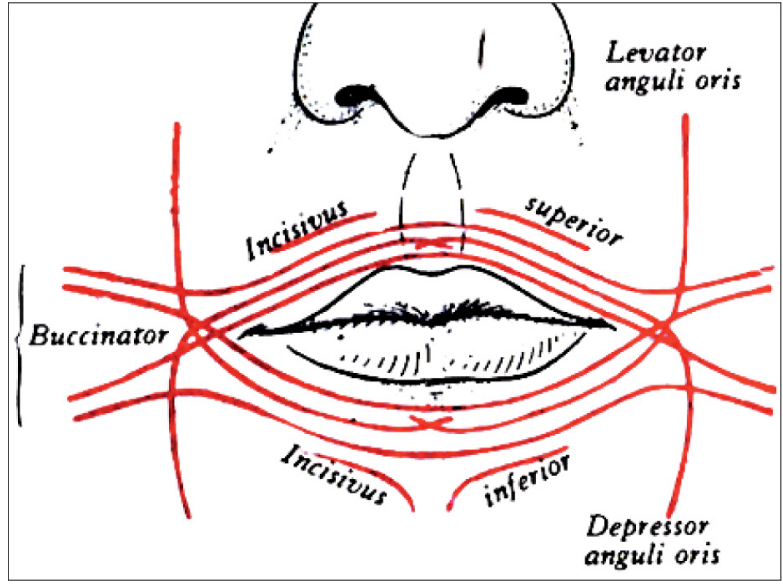

Figure 21

Different muscles supply the upper and lower lips with fibers belonging (after Warwick et al. ${ }^{62}$ ):

- at the height of the upper lip: to rising fibers of the $m$. depressor anguli oris and from the $m$. buccinator which stretch along the $m$. incisivus superior:

- at the height of the lower lip: to the descending fibers of the $m$. levator anguli oris and from the $m$. buccinator which stretch along the $m$. incisivus inferior, by crossing the fibers of the $m$. depressor anguli oris.

Thus the structural organization of the facial envelope seems to be the results of a mechanics where, on each side of the oral fissure, the crossings in the space of the continuum of these fibers are a part of the mechanism that protects each commissure from being torn within the pre-stressed facial envelope. This mechanism also allows for a better understanding of the significance of jugal cleavages, integrated parts of it.

capsules, pre-maxillae and Meckel's cartilages, concentrate stress and deformations on and behind the commissures of the lips, therefore organizing this envelope into three sectors:

- An oronostril ventral sector, split transversely into two parts: superior labium superior alaeque nasi, and inferior labial mental; and bordered laterally by the commissural pillars, situated between the lateral-alar junctions above and the nasolabial sulcus behind and the homolateral extremities of the submental furrow below. At the level of these pillars, there are ascending and descending fibers leading to the commissural crossings.

- Two lateral jugal sectors axially split behind the pillars, with on each side: - a superficial plane whose facial skin muscles of the cheek, attached to the lateral-alar junction, to the orbicularis oris and to the commissure, connects the nasal valve control to the upper lip control; - a deep, buccal plane shaped by the $\mathrm{m}$. buccinator.

\section{- Commissural pillars}

On each side, the commissural pillar extends transversely from the labial commissure to the modiolus. Axially, its lateral border follows the ridge of the dihedral jugal (cheek) muscle (Fig. 22), rising inside the nasolabial sulcus, from the modiolus to the lateral-alar junction, hidden under the superficial plane when the mouth is open. The skin to which it adheres connects to the lateral extremity of the submental furrow below where, adhering to the basal mental periosteum, the skin of the facial envelope is pre-stressed by the cranial mandible posture. Towards each pillar converge the stresses and deformations that the oral fissure medially and the jugal cleavage laterally permanently exert on the lip commissure and its modiolus.

Each pillar is joined at the height of its anchorages by two other concentrations of stress: 

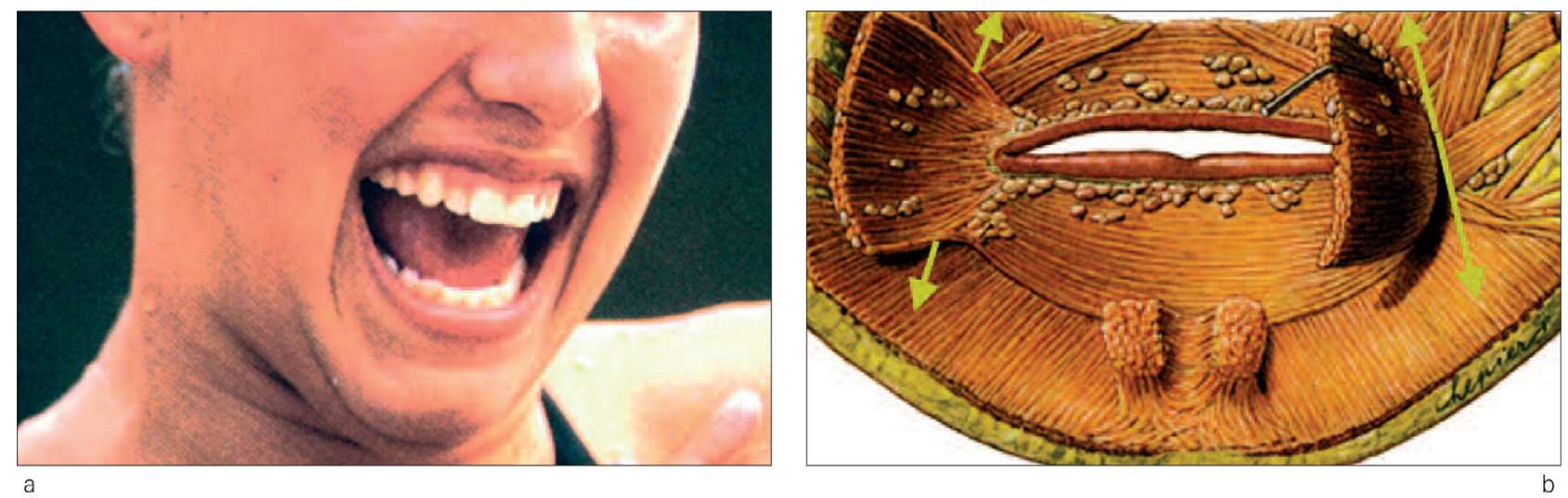

Figure $22 a$ and $22 b$

a: facial envelope; b: jugal diorama (after Sobotta ${ }^{50}$ ).

In view of the role of the the mandible in the postural linkage of the pre-stressed facial envelope, each pillar of the commissures of the facial envelope constitutes a permanent relation between nasal and temporo-mandibular physiologies.

- cranial anchorage, at the height of the lateral alar junction of the nasal cartilages, where concentrated stresses created by the inspiratory deformation of the nasal valve and the wing of the nose and its control; above, less adherent skin folds when the upper lip and the wing of the nose rise;

- caudal anchorage, at the height of the lateral extremity of the sub-mental furrow, where the posture of the mandible concentrates the stresses of the facial envelope, below the mental tubercle raised by the lower part of the pillar when deformations of the facial envelope occur.

\section{- Junction of the lateral alaeque nasi cartilages}

On the nostril extremity of each commissural pillar, at the meeting point of the ventral sector with the lateral sector, the sudden changes in the curvature of the surface of the facial envelope alert the morphologist to the abrupt change in local stresses
(Fig. 18). The ventral concavity of each orbital nasal sector is situated above the ventral convexities of the labium superior alaeque nasi sector. On each side, these changes in the shape of the envelope point out an essential anatomical specificity: the lateral alae nasi junction. It has a double functional orientation:

- the alar cartilage, due to its adherences to it coverings, superficial and deep, is a part of the ventral labium superior alaeque nasi sector that, along with the upper lip, controls oxygen intake;

- the lateral cartilage of the nose, in continuity with the septum nasi, is associated with the jugal (cheek) sector: its facial skin muscles control each nasal inspiration. Capture and inhalation are practically simultaneous.

The neonatal maxillary reveals on its widest coronal section (Fig. 18) that incisor-canine buds and crypts, both deciduous and permanent, surround the nostril edges of the pyriform orifice. Their early development 


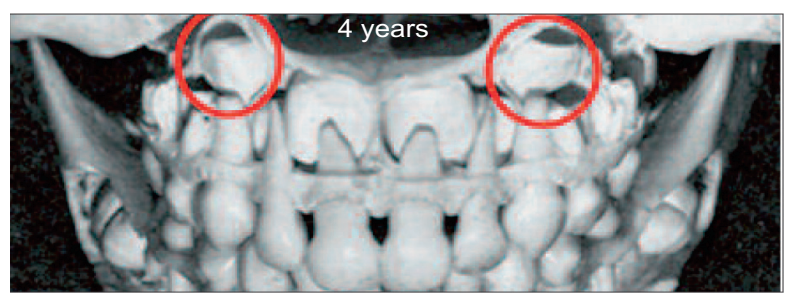

Figure 23

The anatomical relationship of the cranial part of each commissural pillar of the maxillary permanent canine bud is a reality that needs to be recognized if the therapeutist considers the necessity of preventing its impaction (after van der Linden and Duterloo ${ }^{31}$ ).

and their mineralization strongly support local transverse morphogenesis and local physiology.

The bud of the permanent maxillary canine (Fig. 23) supports a key area of the facial envelope, between:

- medially, the lateral wall of the nasal fossae, near the inferior meatus under the head of the lower nasal turbinate; - dorsally, the anterior-lateral wall of the maxillary sinus; ventrally, the lateral wall of the frontal process of the maxilla and the nostril portion of the corresponding commissural pillar of the envelope. This bud appears at the $4^{\text {th }}$ fetal month. Its development and its migration towards the ventral part of the lateral sector of the arch are closely related with the nostril control by its commissural pillar. Preventing transverse shrinkage of the nostril portion of the pyriform aperture, at the time of the eruptive migration of this canine, is an important objective for a snoring patient. It amounts to preventing the impaction of this tooth and to reestablishing an optimal width for the nostril openings.

\section{- Sectorial dominance}

Depending on the main direction of the stretching of the commissural pillars, the sectorial dominances of the functional activity of the facial envelope contrast two oral nostril postures (Fig. 14):

- The dominance of the labial sector characterizes dolichofacial typology and presents: low and pinched nostrils, narrow and horizontal nostril openings, fleshy upper lip, short philtrum, prominent philtral crests, high lower lip, flat chin.

- The dominance of the jugal sectors characterizes the brachyfacial typology and presents: wide and obliquely ascending nostril openings, narrow nasal valves, thin and stretched upper lip, flat philtrum and philtral crests, distalized and raised labial commissures, accentuated nasolabial sulcus, everted lower lip, prominent chin.

These postures limit the extent of the modalities of using the facial envelope depending on the two main directions of deformation of the oral fissure.

\section{6 - MORPHO-PHYSIOLOGIC INTEGRATION OF LABIUM SUPERIOR ALAEQUE NASI}

The development of the labium superior alaeque nasi is enhanced by various contributions, interacting on a small scale: 
- ventral projection of the nose, attributed to the growth of the septum nasi;

- development of the maxillary central incisor crowns, activating with the pre-maxillae the transverse unfolding of inspiratory intake apparatus of ventilatory fluid (Fig. 2);

- amniotic breathing that, by detaching the alar cartilages from the lateral wings of the capsule, plays a major role: - in the development of the nostrils, palate, turbinates and valves; - in the nasomaxillary, pterygoid and velar tridimensional projection; - and in the elongation of the anterior cranial base (Fig. 24).

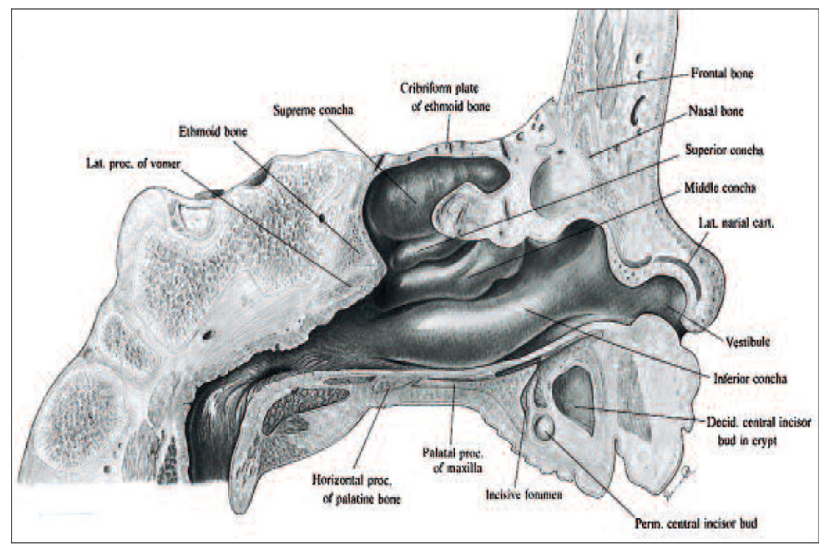

Figure 24

A craniomaxillary sagittal section of a newborn lafter Bosma ${ }^{7}$ ), besides the proportions of its nostrils, nasal fossa and inferior concha, shows the quasi-horizontal situation of the pterygoid process, the importance of the soft palate and the location of the orifice of the Eustachian tube at the height of the floor of the palate.

These morphological characteristics bear the imprint of the efficacy of amniotic breathing. The neonatal change of ventilatory fluid will have very different consequences on craniofacial morphogenesis in developing, at the height of the walls of the pulmonary alveoli, a superficial tension that did not previously exist.

\section{6 - 1 - Tilting movement of the nostrils ${ }^{5}$}

In utero, the evolution of the human facial profile shows the tilting developmental movement of the nostrils. They are still sealed at 9 fetal weeks (Fig. 25), almost frontally orientated and projected in the ventral direction by the growth of the nasal capsules $^{49}$. Then they tilt in the caudal direction as a result:

- of the transverse widening of the nostril openings by the early $\left(6^{\text {th }}\right.$ fetal week) development of the maxillary central incisor crowns ${ }^{57}$, a preparation for the appearance of the sub-nasal fold (Fig. 26);

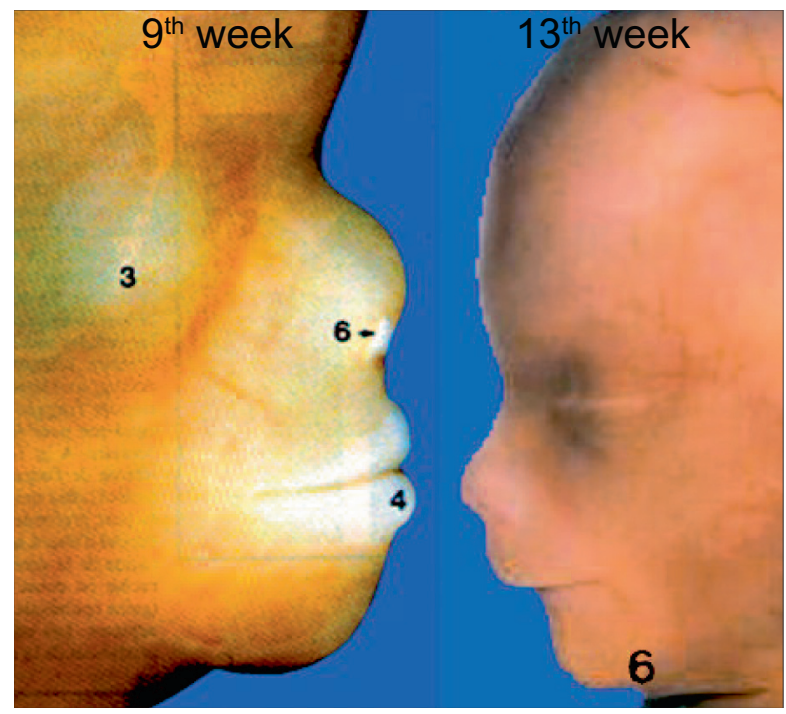

Figure 25

The container-content relationship of the fetal nose with the amniotic fluid animates the changes in the shape of the lateral capsular wings starting at the $11^{\text {th }}$ week, linked to alternating inhalation and exhalation of amniotic breathing. Very soon after beginning, this alternation individualizes the alar cartilages and ventrally tilts the nostrils (after England ${ }^{17}$ ). 

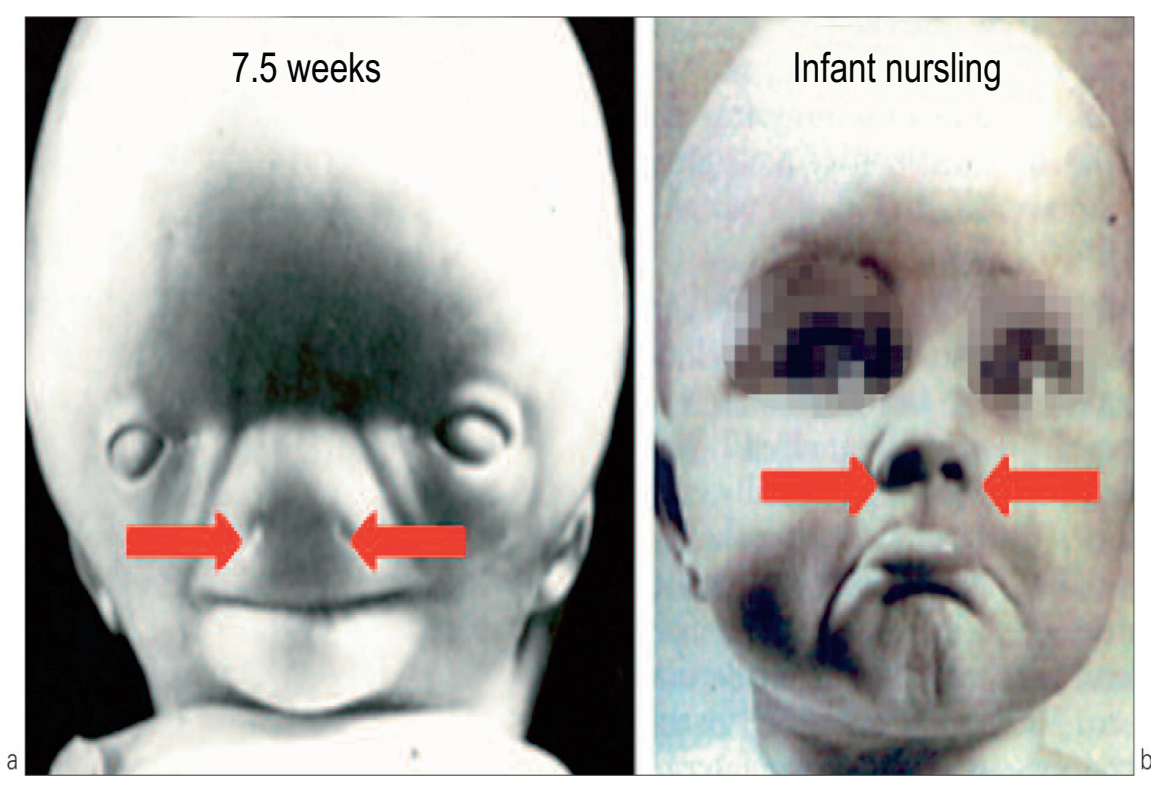

Figures 26a and 26b

7.5 weeks Infant nursling

The widening of the nostril openings, in conjunction with the crowns of the maxillary central incisor causes the appearance of the sub-nasal groove at the same time that the upper lip recedes under the nostrils and that the labial columella angle closes.
- of transverse deformations of the lateral wings of the capsule due to amniotic breathing that individualizes alar cartilages ${ }^{54}$.

\section{6-2-Development of the inspiratory intake apparatus}

At the height of the septo-pre-maxillary junctions, the maxillary central incisor coronal widening, associated with the capsular growth and expiratory thrust of amniotic breathing on the nostrils, contributes to horizontal development of the nostrils by placing their ventral extremities as an awning above the upper lip, revealing the transverse sub-nasal fold.

This important stage in the morphogenesis of the labium superior alaeque nasi inspiratory intake apparatus of ventilator fluid begins with breathing, at the $11^{\text {th }}$ fetal week.

The presence of a concentration of stress at the angle of each nostril opening along with the columella, might foster, on each side: - the opening up of the superficial nostril opening; - the organization of the fibers of the $m$. depressor septum nasi at the labio-columellar junction ${ }^{47}$; - the lifting of the philtral crest and the formation of cupid's bow (Fig. 26 and 27). The dysmorphisms that accompany $\mathrm{SMCl}$ and Unilateral Maxillary Labial Clefts support the opposite of these mechanisms.

\section{6 - 3 - Solitary maxillary central incisor syndrome (SMCl)}

In normal conditions, the larger mesiodistal crown development ${ }^{31}$ of each maxillary central incisor, by placing early on in utero the cervical region of this tooth (deciduous then permanent) in contact with an individual nostril opening, would prevent the restrictive effects of inspiratory intake on the transverse expansion of the corresponding nostril opening. 

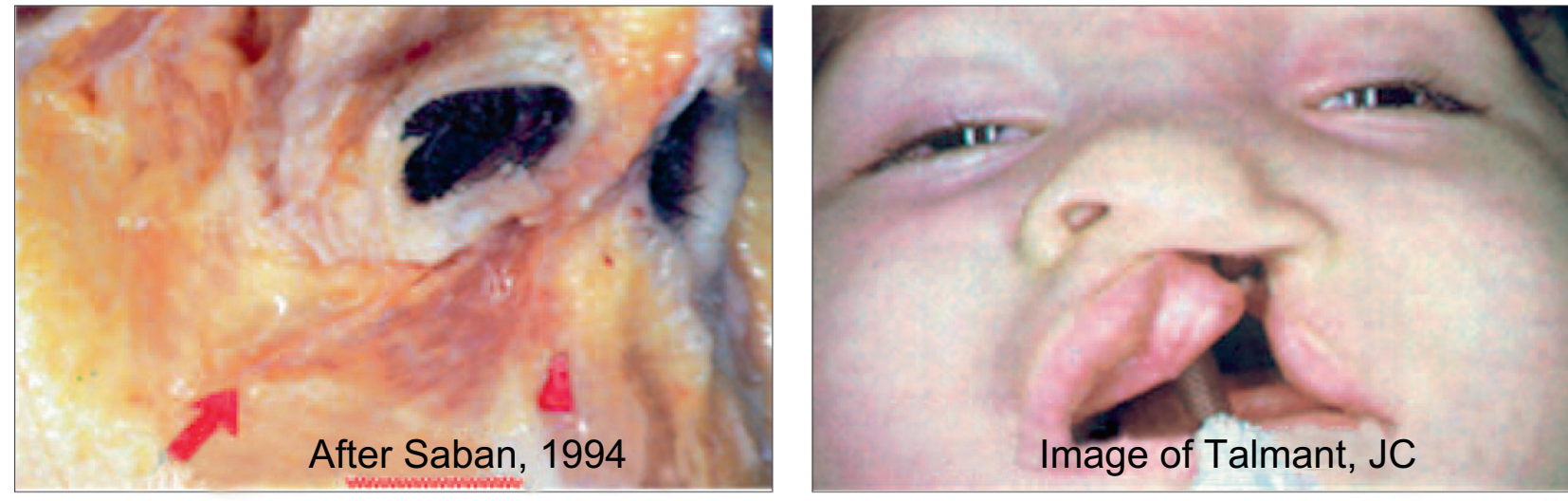

a

Figures $27 \mathrm{a}$ and $27 \mathrm{~b}$

The important static and dynamic changes on the height of the nasal columella angles are the source of concentrations of stress that: - open the superficial nostril orifices; - organize the fibers of the $\mathrm{m}$. depressor septi nasi at the junction of the upper lip with the columella; - raise the philtral crests (after Saban ${ }^{47}$ ).

The dysmorphisms which accompany SMCl and complete unilateral labiomaxillary clefts support this hypothesis a contrario.

For Belden ${ }^{2}$ (Fig. 28), the solitary maxillary central incisor syndrome (SMCI) is associated with the failure of the transverse development of the pyriform orifice (no inter-incisal suture), of the nostrils, of the nasal fossae, of the maxillary palate, and also with the absence of the philtrum, of cupid's bow and of the frenulum labii superioris. In both cases, the identical transverse neonatal diameters of the nostril portion of the pyriform orifice and of the sum of the diameters of the crypts of the existing maxillary central incisors, observed in a normal newborn as well as in cases of $\mathrm{SMCl}$, support the mechanical nature of such a relationship. In circumstances such as these, the narrowness of incisor 'swing bar' shows its inability to contain the restrictive effects of the dynamic inspiration on the transverse development of the nostril openings. The hypertrophy of the nostril borders of the pyriform aperture, the result of the expiratory tractions, accompanies the asymmetric ventral projection of the nostrils. The septal convexity (dilated median meatus) looks at the side where the blockage of the amniotic flow is the weakest, in this case the side that is opposite to that of the agenesis.

\section{6 - 4 - Unilateral labio-maxillary clefts}

Dysmorphisms observed in cases of unilateral labiomaxillary clefts are also very conspicuous.

The alterations in the containercontents relationship that the dysmorphisms present near the facial transit of the amniotic fluid related to fetal breathing (Fig. 29), while bearing the mark of the side of the malformation, provide evidence of the physical origin of associated deformations. Their identical mechanisms make them predictable, although the 

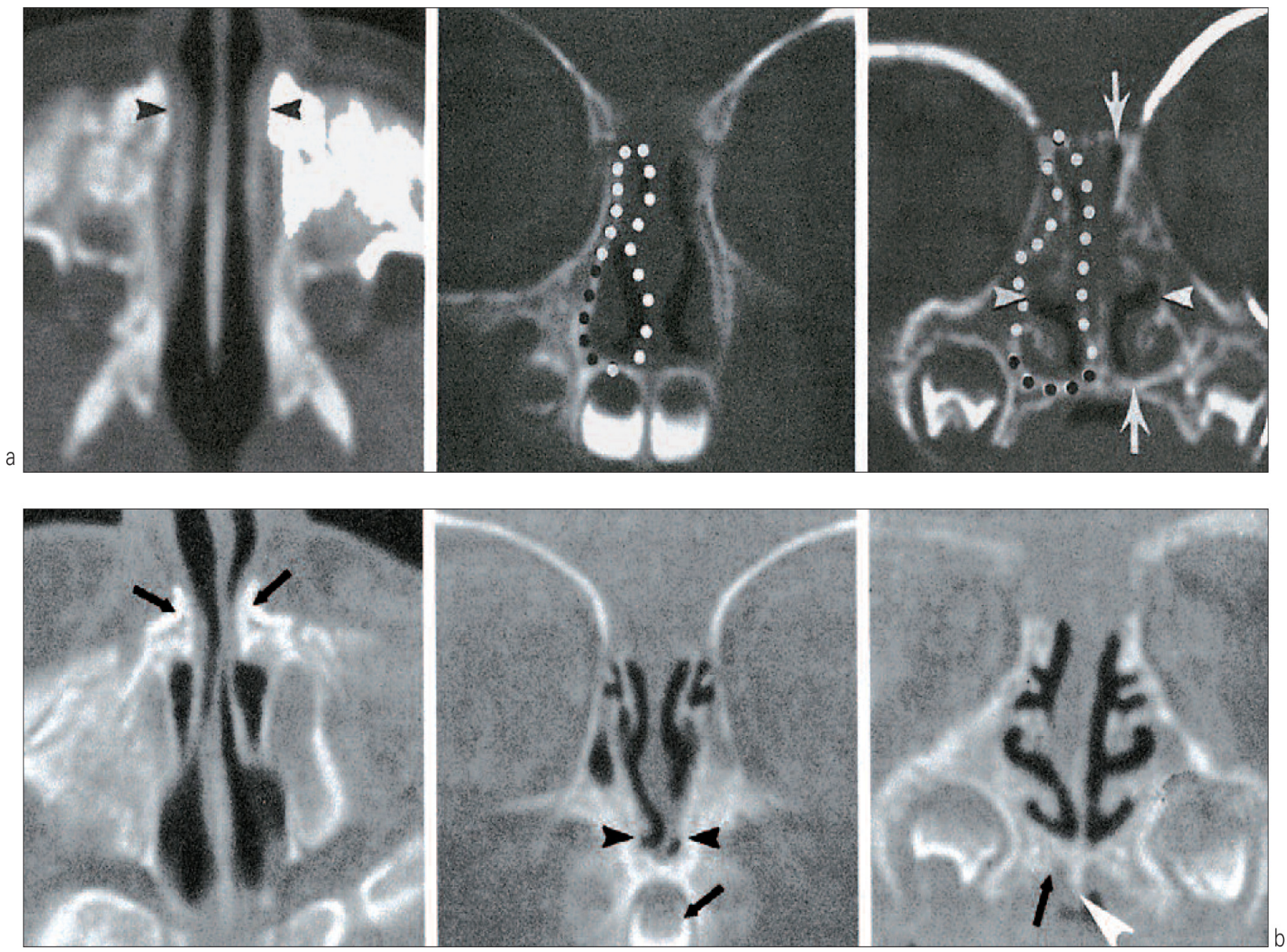

Figures 28a and 28b

Theses tomographic sections of the head of newborns are: - left, axial; - center, coronal at the pyriform level; right, coronal at the palatine level (after Belden ${ }^{2}$ ).

a: In the normal newborn the neck of each maxillary central is situated very close to contacting the base of the corresponding nostril. By its transverse dimension and by its mechanical resistance, this crown has stabilized the transverse dimension of the nostril openings against the mechanical restrictive effects of amniotic breathing. The presence of two central incisors and the precocity of their development are therefore necessary for the proper development of the two nostril openings.

Elsewhere, the proximity of the pulps that are present in the incisor crowns under the nostril openings turns the pulps into thermal sensors able to be integrated into the thermoregulatory process along the hypothalamic-pituitary axis above to the cartilaginous nasal capsules and Involving the nasal circulation of amniotic fluid. The frequency of midline anomalies associated with stenosis of the pyriform orifice and the agenesis of the maxillary central incisor bears witness to this fact. ${ }^{22}$

b: In SMCl, the existence of a solitary maxillary central incisor does not suffice to sustain the normal transverse development of the two nostril openings. Stenosis of the pyriform orifice has led to trouble in amniotic breathing, particularly in the nasal fossae located on the side of the missing incisor, and generating septal (their convexity reduces the nasal fossa on the side opposite the missing tooth), turbinate and nostril dysmorphisms that are visible on the axial tomogram of this infant. 


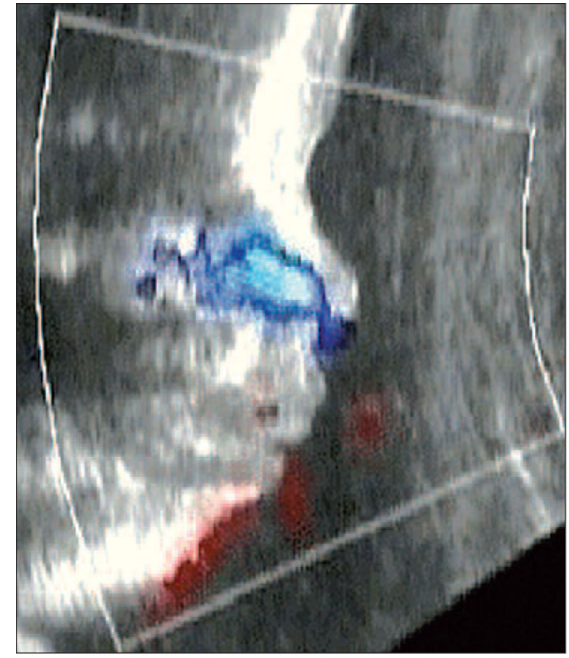

a

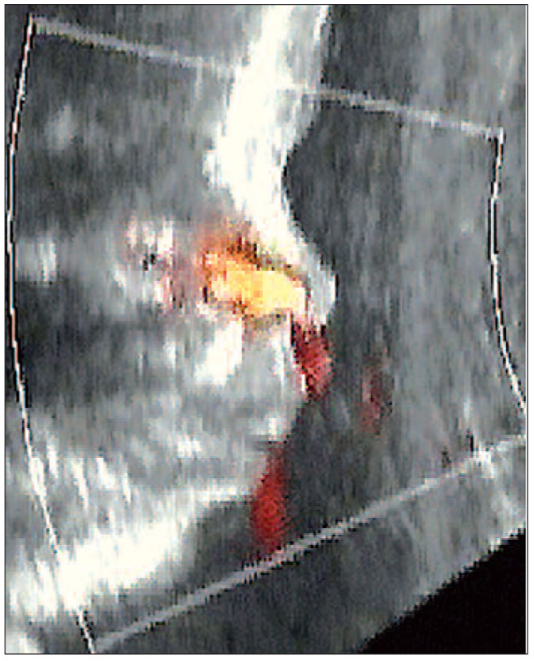

b

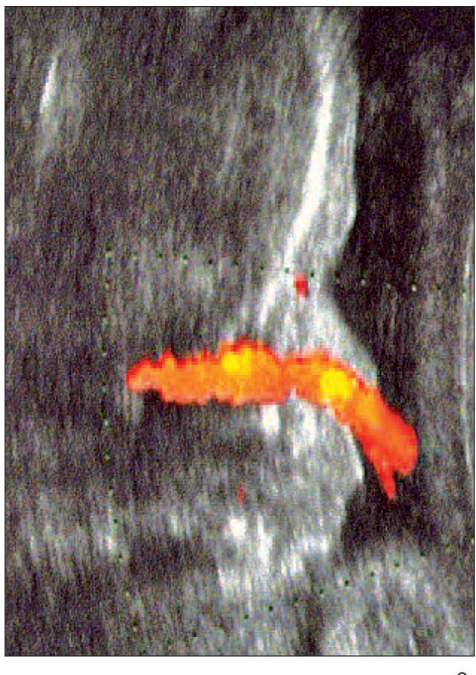

Figures 29a to $29 c$

a: inspiration; b: expiration; c: cleft lip, alveolus and palate

These normal dynamic echograms (a: at inspiration, b: at expiration) and in a case of a unilateral lip, alveolar and palatal cleft (c: at expiration) demonstrate the hydrodynamic disruptions which follow a malformation primitively localized and the deformations which are provoked while working under the "abnormal anatomical conditions". These disturbances add deformations to the initial malformation (Documents of Dr. Cl. Talmant).

genomes of affected patients are different.

Even if it is unilateral, the labiomaxillary cleft alters bilaterally the turbinate morphogenesis, and therefore the guidance of ventilatory flow of amniotic fluid. A dynamic ultrasound shows that: - in normal conditions the expiratory flow, pinched by the surface opening of the nostrils, exits tangential to the upper lip; when a fissure is present, the expiratory flow exits mainly from the side of the fissure (that offers least resistance), pinched between the alar portion of the nostril and the lower lip.

As empty nose syndrome (after bilateral inferior turbinectomy) clearly shows, a unilateral cleft confirms the importance of turbinate guidance of ventilatory fluid (amniotic as well as aero) for the morphogenesis of the container and the contents, from the nostrils to the soft palate and then conversely, for inhalation and exhalation, extra and intra utero. Far from being a luxury, this guidance is a physical necessity.

Regardless of the side of the cleft, the labio-nostril features are asymmetric (Fig. 30); neither side is unscathed. Once again, the septal convexity faces the weak side of expiratory amniotic pressure, in this case on the cleft side. The plane of the septum nasi ${ }^{27}$, that is optimal both in utero and extra utero, stems therefore from the symmetry of pressure waves to which normal ventilation subjects the two sides of this septum.

The asymmetry of nasal amniotic dynamics involves even more facial dysmorphisms ${ }^{27}$ : - stretching of the alar cartilage on the cleft side, linked to the deviation of the ventral part of 


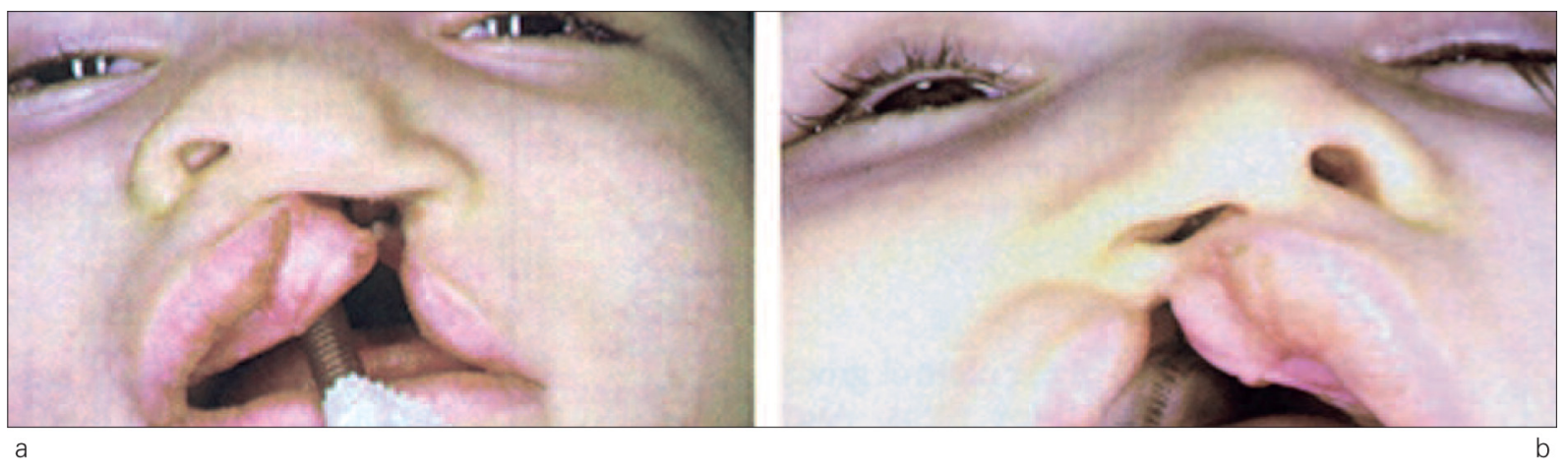

Figure 30a and $30 b$

The complete unilateral lip, alveolar, palatal cleft, left or right (documents of Dr. J.-C. Talmant), shows how the deformations associated with the malformation are important. These images do not show the associated dysmorphisms of the turbinates.

the septum; - reduction of the sagittal projection of the nasal capsules that is secondary to the decrease in overall growth that affects the nostrils and capsular wings; - significant bilateral turbinate dysmorphisms due to the imbalance of the septal-nostril guidance; - shortness of the anterior cranial base.

In order to provide some important complementary information, we note that the mechanisms of facial growth of the fetus presenting a unilateral labio-maxillary cleft, are apparently normal, but operate under abnormal anatomical conditions. The growth curves of their pre-maxillae ${ }^{36}$ remained the same as those of a similar group from 8 to 14 fetal weeks, confirming that the same time of normal growth preceded the beginning of amniotic ventilation in both groups but differed between 14 to 21 fetal weeks. For the authors we have cited, an evolution like this favors a dysfunctional deficit in the mediofacial growth rather than a primitive mesenchymal deficit.

\section{6 - 5 - Contributions of the maxillary incisors to nostril adjustment}

Extra utero, under normal conditions (Fig. 31), as long as the permanent central incisor crowns remain close to the nostril openings, the adjustment of the transverse nostril diameter of the pyriform aperture to the sum of the mesio-distal diameters of the permanent central incisor crypts is maintained $^{32}$. A stable situation such as this, over time and from a child to another, in the course of a slow and silent morphogenesis of the permanent maxillary central incisor crowns, supports the mechanical origins of this adjustment and that of the morpho-physiologic integration of the labio-nostril or labium superior alaeque nasi sector of the facial envelope.

But at the beginning of the mixed dentition stage, the eruption of the permanent central incisors empties the pre-maxillae of a part of their contents enclosed under the nostril 


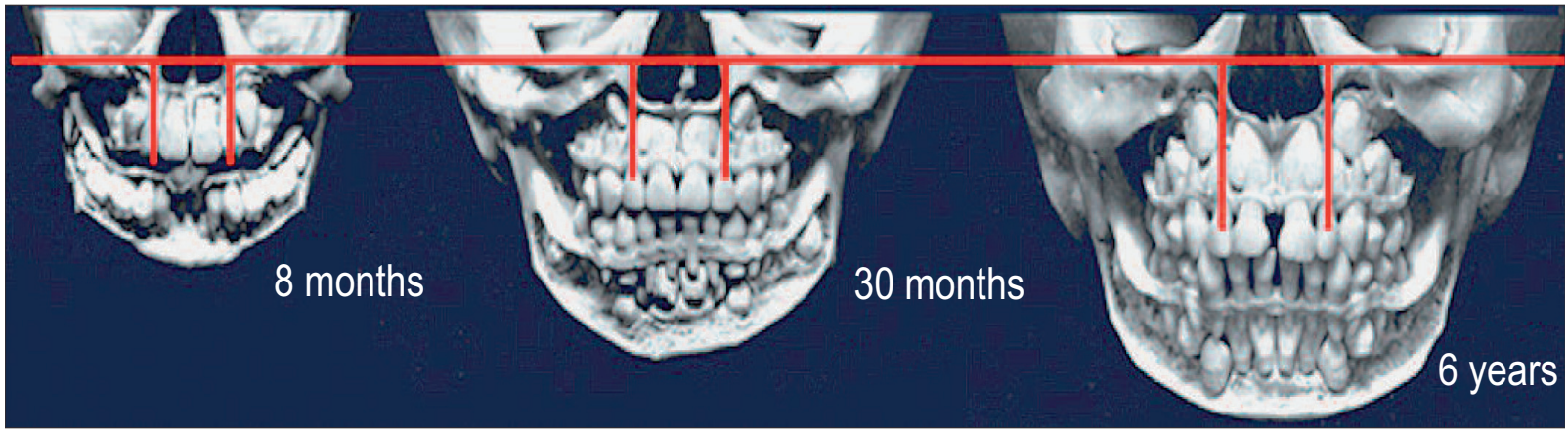

Figure 31

8 months 30 months 6 years

The anatomical relationships between the proximity of, and the proportions of, the transverse diameters of the contents of the crypts of the permanent maxillary central incisors with the nostril openings in an 8 month old subject (left), 30 months (center) and 6 years (right) do not change from birth to 6 years (after van der Linden and Duterloo ${ }^{31}$ ).

The buds of the maxillary central incisors and their crypts are associated in their work in the expansion and development of the nostril openings of the pyriform orifice.

openings. Narrowing of their developing roots follows the significant widening of each permanent incisor crown. The septa between the roots can also be very long and thin (Fig. 32).

In the dysfunctional context where pathologic snoring causes the vibrations of the soft palate that are transmitted to the inspiratory air and shake the alae nasi and the commissural pillars. These vibrations cause medial deviations in the eruptive paths of the canines and they shrink the transverse labium superior alaeque nasi support. The result is an incisor-canine apical compression that reduces the nostril openings.

By correcting incisor-canine crowding before or during canine migration, pre-maxillary orthopedic expansion, widening the transverse distance of the commissural pillars, also optimizes the transverse labium superior alaeque nasi support that is so impor- tant for the inspiratory dynamics of the mobile nose and postural tone of the facial skin muscles ${ }^{57}$. To have a lasting morphological outcome until complete recovery of the Optimal $\mathrm{Na}$ sal Breathing, a simple orthopedic procedure performed at the appropriate time, makes it possible to reestablish all the functioning that an optimal oronasal and morpho-physiologic integration can offer, provided that the nasal mucosa pathology is still reversible.

For Cole ${ }^{11}$, the shape of the nostrils is "stabilized by cartilage and bone, modulated by the voluntary muscles and regulated by the erectile tissues." In addition to these factors, we must associate the eruption of the transverse support that the maxillary central incisor crowns contribute to the nostril openings. This support lasts up to 6 to 9 years, as long as the proximity of the openings continues with the 


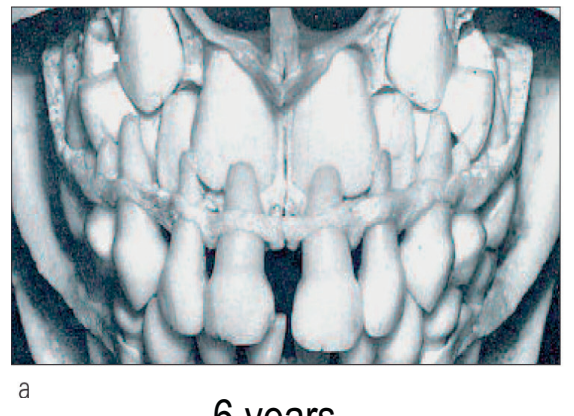

6 years

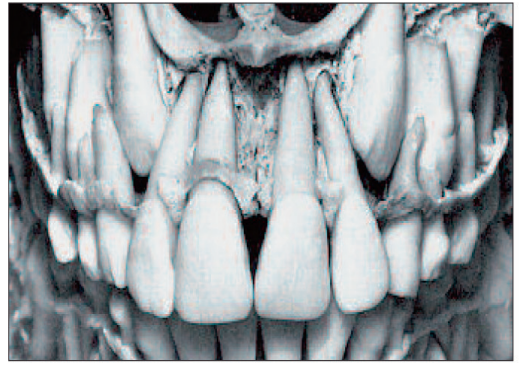

9 years

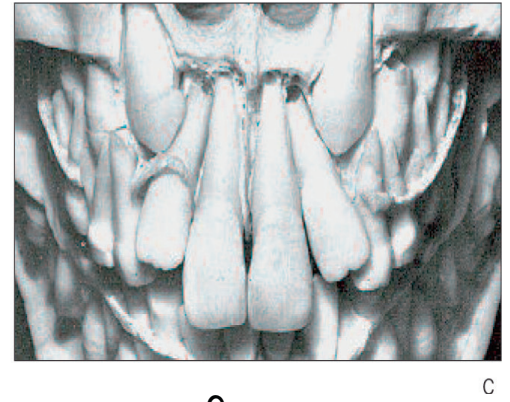

9 years

Figures $32 a$ to $32 c$

a: 6 years; $b: 9$ years; $c: 9$ years

The eruption of the permanent maxillary central incisors is a critical phase for the labial nostril support, and therefore for dynamic inhalation through the nostrils. This is the case when ENT pathological antecedents had altered the nasal mucosa and provoked hypertrophy of the pharyngeal lymphoid tissues. The physiological adaptation to the augmentation of nasal resistance features the alae nasi vibrations caused by snoring that generate an incisocanine apical compression (after van der Linden and Duterloo ${ }^{31}$ ).

central incisor necks. Then, it diminishes when the occlusal migration of their crowns separates them from the nostril openings. And this narrowing is excessive when the nasal dysfunction forces the adoption of an unfavorable inspiratory posture that is indicated by the shape assumed by the incisor-canine arc. Clinically, the labium superior alaeque nasi postural contribution to the dysmorphism of incisor-canine arc is detected when: the low mandible posture axially stiffens the commissural pillars, stretches the nose, pinches the nostril openings and results in an ovoid arch; or when the transverse stiffness of the pillars combining with the mandible posture, opens the nostril openings, flares them out and establishes an upsilon-shaped arch, while the genial control of the pinched valves distally raises the alar cartilages. In both cases, a dysfunctional morpho-physiologic integration of labium superior alaeque nasi is in place.

\section{6 - 6 Treatment for agenesis of the maxillary lateral incisors}

The treatment for agenesis of the maxillary lateral incisors proceeds along this line of thinking. The rule is simple: do not harm the recovery of Optimal Nasal Breathing ${ }^{55}$ (ONB). Therefore, the goal is to optimize the labium superior alaeque nasi support. The way we do this is: to open lateral incisor spaces by expanding the premaxillae; to compensate the agenesis with a prosthetic device to relieve the labial pressure from the alveolar process. The functional outcome for a 13 year old asthmatic patient (a case of Dr. Deniaud), that was reevaluated 8 years after the end of dentofacial orthopedic treatment, demonstrated that the recovery of an optimal labium superior alaeque nasi support had made it possible: - to reestablish the ONB; - to eliminate the asthma: the TVC > 106\%; - there was a spurt of remedial statural growth. 


\section{7 - CONCLUSIONS}

The integration of the oronasal region of the face with upper airways is an anatomical and physiological fact whose expression is not solely neurological. Intra as well as extra utero, the soft nostril tissues, the turbinates, the tubal and velo-pharyngeal soft tissues that are directly exposed to the dynamics of ventilatory fluid, must be subjected to this mechanical stress. The expansion of these soft tissue territories during the growth period is marked by a great frequency of snoring and other ENT pathologies; practically the nights of every patient were interrupted by sleep apnea $195 \%$ in the statistics from Dejean ${ }^{15}$ ).

There is a necessary corollary, the postural activity of the facial envelope of patients presenting a malocclusion shows that the most accessible at rest breathing modality forced them to adopt a certain sectorial dominance. The labium superior alaeque nasi inspiratory posture reveals the muscle tone adopted to shape the pyriform and maxillary incisor-canine supports, and to therefore satisfy the requirements of the most efficient breathing modality; and all the while, the labial mental and lingual soft tissues shape the mandibular alveolardental forms and the chin, and adapt their posture to swallowing and to changes in breathing. The craniomandibular and craniorachidian postures comply with the required oro-nasopharyngeal integration ${ }^{56}$.

For this clinician, these postures are a series of symptomatic alerts that help to detect a dysfunctional oronasal and morpho-physiologic integration. They often appear at the beginning of the mixed dentition phase, when the labium superior alaeque nasi support is weakened by the maxillary incisor-canine arc that is completely erupting, and even from the fact that nasal base is narrowing during the eruptive migration of the canine buds. They may have started earlier, in relation to the failure of the transverse development of the nasal fossae and of the maxillary arch, linked to ENT pathologies and snoring. In each of these examples, oronasal dysmorphisms are associated with oronasal dysfunctions.

For at rest breathing, the facial envelope actively controls the initial conditions: nasal, oral or mixed of passage through the upper airways, with their postural corollaries. In a particular case, "Optimal55" Nasal Breathing can be defined physiologically as "breathing at rest, spontaneously and exclusively nasal, including at night, when prone during sleep". This is how a normal newborn breathes. ONB in fact combines an intricate complex of physiological and biological manifestations related to air mucosa interactions. As a result of nasal valve control by the facial skin muscles, the secretion of healthy nasal mucosa and the delivery of heat via turbinate blood, evaporation, stimulated by the acceleration, depression and orientation of inspiratory air when it exits by the valves, ensures the transfer of heat from the turbinate blood to the inhaled air. In the course of the same physical operations, ONB therefore produces the humid heat destined 
for the bronchial alveolar air and the corresponding cooling blood transmitted by the cavernous sinuses to the hypothalamus hypophysis axis. Quantitatively, the nasal production of bloody negative calories by ventilation, governed by the structures of the Central Nervous System near the cavernous sinuses, is as great as that of the calories destined for the bronchial alveoli. And the functional integration of these transfers shows all the dimension of the all too often underestimated nasal thermodynamics when it is the product, frequently altered by snoring, of a specific interaction between air and nasal mucosa.

Since it is necessary to overcome half of the total resistance of the airways during the first half of its nasal transit, at rest nasal inhalation accomplishes work that is more important than oral inhalation. However, the "comfort" that it brings explains why nasal breathing is preferred. This type of breathing is in essence the result of the significant efficiency of thermal exchanges normally offered by the upper airways, and stems from: the evaporation that the nasal valves effect; the specific qualities of the turbinate mucous and its vascular network; - and the specific needs of structures close to the cavernous sinuses, since the ambient heat does not facilitate the expulsion of calories to any degree.

However, uncontrolled mechanics, triggered by snoring, produces vibrations that cause traumatic lesions on the soft palate, the pharyngeal walls and the turbinate mucosa the extent of which has yet to be determined. The anatomy and the physiology of the pillars as well as the labium superior alaeque nasi and morphophysiologic integration confirm this damage. These lesions add to the list of medical indications for DFO treatment of nasal insufficiency including: - snoring by infants and adolescents; - chronic sore throat and ear infection; - lymphoid hypertrophy of the pharynx; - obstructive sleep apnea. Early treatment is evidently very efficient as long as the lesions are still reversible.

The high prevalence of dysmorphisms of the maxillary incisor-canine arc, that are either the cause or the consequences of nasal breathing difficulties affecting the nostril openings and/or the nasal valves suggests that the morpho-physiologic role of the labium superior alaeque nasi substructure of the facial envelope is quite important. But before recognizing this role, we had to call into question numerous facets of this poorly constructed complex:

- the independence of the teeth and the maxilla;

- the intangibility of the maxillary intercanine diameter;

- the adequacy of dental extractions for orthodontic purposes for children and adolescents;

- the accessory morphogenetic role of nasal breathing;

- the work of dentofacial orthopedics is confined to the oral region.

In spite of the importance of the problems raised, a number of questions were left unanswered:

- the role of the maxillary incisors in the development of the face;

- the mechanics of the soft tissues of the facial covering;

- the regulation of the postural activity of the facial skin muscles; 
- the morphogenetic role of nasal breathing;

- the transverse development of the nasal fossae;

- procedures for maxillary expansion;

- the etiology of obstructive sleep apnea ${ }^{59}$;

- the interaction between the different morphogenetic processes...

Above all, no concept sufficiently explained the importance of the soft tissues of the face, except for descriptive anatomy. Since this complex leads to a better understanding of the development ${ }^{18}$ of malocclusions, it must also place greater importance on the use of data from embryology, anatomy, physiology, physics and its coupling with genetics, in order to rapidly identify important relationships. The integration of this data reveals etiopathogenic concepts that are more connected to reality, such as the container-contents relationship (this mechanical aptitude for reciprocal morphological adaptation), and oronasal and morpho-physiologic integra- tion; this can lead to therapeutic strategies whose objectives are both better adapted and clearly more productive. And, far from being an end, this technique is still a means for effectively optimizing facial morphogenesis by giving the dolichofacial patient, for example, the ability to construct a chin without surgery.

From now on, the efficiency of a procedure that calls for the skills of a practitioner of DFO, will require that orthodontists deepen their knowledge of the mechanics of the structures for which they optimize the morphogenesis, and will also require that they be more attentive to the overall functional aspects of the complex into which the face is integrated.

With all due respect that is owed to the face of each patient. This is from a "guy from the Nasal Academy" who, as you might suspect "wants to make orthodontic molds breathe"!

\section{BIBLIOGRAPHY}

1. Bak P. How nature works. The science of selforganized criticality. New York: SpringerVerlag, 1996.

2. Belden CJ, Mancuso AA, Schmalfuss IM. CT features of congenital nasal piriform aperture stenosis : initial experience. Radiology 1999;213:495501.

3. Berthet $\mathrm{J}$, et al. Dictionnaire de Biologie. Bruxelles : éditions De Boeck Université, 2006.

4. Bitbol M. La nature s'organise comme les poupées russes. Les dossiers de la Recherche 2011;43(5):22 7.

5. Blechschmidt E. Principles of biodynamic differentiation. Dans: Symposium on development of the basicranium, JF Bosma (éd) DHEW Publication $\mathrm{N}^{\circ}$ (NIH) 77-989. Bethesda, Maryland 1976:54-76.

6. Blechschmidt E. The ontogenetic basis of human anatomy. Berkeley, Californie : North Atlantic Books, 2004.

7. Bosma JF. Anatomy of the infant head. Londres: The Johns Hopkins University Press, 1986.

8. Changeux JP, Connes A. Matière à pensée. Paris : Odile Jacob, 1989. 
9. Cho JG; Witting PK; Verma M; Wu BJ; Shanu A; Kairaitis K; Amis TC; Wheatley JR. Tissue vibration induces carotid artery endothelial dysfunction: a mechanism linking snoring and carotid atherosclerosis? Sleep 2011;34(6):751-7.

10. Chouard $\mathrm{CH}$, Charachon R, Morgon A, Cathala HP. Fonction motrice. In : Anatomie, pathologie et chirurgie du nerf facial. Paris : Masson, 1972.

11. Cole P. The respiratory rôle of the upper Airways. St. Louis: Mosby Year Book, 1993.

12. Couly G. Le mésethmoïde cartilagineux humain. Rev Stomatol Chir maxillofac 1980;81:13551.

13. D'Arcy Wentworth Thompson. On growth and form. Cambridge University Press, 1961. Traduction française : Forme et croissance. Paris : éd. du Seuil, éd. du CNRS, 1994.

14. Davies JA. Mechanisms of Morphogenesis: The Creation of Biological Form. Burlington, MA.: Elsevier Academic Press, 2005.

15. Dejean Y., Crampette L., Billard M., Gross F. Intérêt de l'examen ORL dans le syndrome d'apnée au cours du sommeil. Cahiers ORL 1985;20:57186.

16. Douady S, Couder Y. La physique des spirales végétales. La Recherche 1993;24: 26-35.

17. England MA. Atlas en couleurs de la vie avant la naissance. Paris : Maloine, 1983.

18. Ewings EL, Carstens MH. Neuroembryology and functional anatomy of craniofacial clefts. Indian J Plast Surg. 2009 October; 42(Suppl): S19-S34

19. Farge E. L'embryon sous l'emprise des gènes et de la pression. Pour la Science mai 2009;379:429.

20. Gola R. La rhinoplastie fonctionnelle et esthétique. Paris : SpringerVerlag France, 2000.

21. Gordon JE. Structures et matériaux. Paris : Belin, 1994.

22. Guilmin-Crépon S, Garel C, Baumann Cl, Brémond-Gignac D, BailleulForestier I, Magnier S, Castanet M, Czernichow P, Van Den Abbeele T, Léger J. High proportion of pituitary abnormalities and other congenital defects in children with congenital nasal pyriform aperture stenosis. Pediatr Res 2006; 60(4):47884.

23. Hahn TTG, McFarland JM, Berberich S, Sakmann B, Mehta MR. Spontaneous persistent activity in entorhinal cortex modulates corticohippocampal interaction in vivo. Nature Neuroscience 2012;15:1531-8.

24. Houchmand-Cuny M. Etude des variations de I'activité électromyographiue paranasale au cours des expansions transversales maxillaires par Quad-Helix. Mémoire CECSMO, Nantes, 2003.

25. Jacobs MR. The fibre tension of woody stems with a special reference to the genus Eucalyptus. Common for Bur Aust Bull 1938;22:36.

26. Jacrot B, PebayPeyroula E, Mache R, Debru Cl. Physique et biologie : une interdisciplinarité complexe. Paris: EDP Sciences, 2006.

27. Kimes KR, Siegel MI, Todhunter J. Relative contributions of the nasal septum and airways to total nasal capsule volume in normal and cleft lip and palate fetal specimens. Cleft Palate J 1988;25(3):283-7.

28. Larsen WJ., Dhem A. Embryologie humaine. Bruxelles: De Boeck Supérieur, 2003.

29. Laughlin R. Un univers différent. Paris : Fayard (Le temps des sciences), 2005.

30. Laughlin R. Les lois physiques ressemblent à un tableau impressionniste. La Recherche 2007;405: 3840.

31. Linden FPGM van der, Duterloo HS. Development of human dentition. An Atlas. Harper \& Row, 1976

32. Marc F. Étude par scanographie à rayons $X$ des corrélations entre la largeur des incisives maxillaires et les dimensions transversales de l'orifice piriforme. Mémoire de certificat d'études cliniques spéciales mention orthodontie. Nantes : Univ Nantes, 2005. 
33. Mathieu JP, Kastler A, Fleury P. Dictionnaire de Physique. Paris : Masson, Eyrolles. 1983.

34. Mattheck C, Kubler H. Growth stresses. In : Wood - The internal optimization of trees. Berlin : SpringerVerlag, 1995.

35. Miannay D. Mécanique de la rupture. Les Ulis : Editions de la Physique, 1995.

36. Mooney MP, Siegel MI, Kimes KR, Todhunter J. Premaxillary development in normal and cleft lip and palate human fetuses using three-dimensional reconstruction. Cleft Palate J 1991;28(1):4953.

37. Netter FH. Atlas of human anatomy. Ciba-Geigy Corporation, 1989.

38. Paulsen FP, Steven P, Tsokos M, Jungmann K, Müller A, Verse T, Pirsig W. Upper airway epithelial structural changes in obstructive sleep-disordered breathing. Am J Respir Crit Care Med, 2002;166(4): 5019.

39. Penrose LS. Distance, size and shape. Annals of Eugenics 1954;18:33743

40. Plas E, Deliac P, Garuet Lempirou A, Caix P, Bioulac B. The buccinator muscle: an original morphogenetical study. Morphologie 2004;88(280):2730.

41. Purves D, Augustine GJ, Fitzpatrick D, Hall WC, LaMantia AS, McNamara JO. Neurosciences. $3^{e}$ éd. Bruxelles : De Boeck, 2008.

42. Radlanski RJ. Contributions to the development of human deciduous tooth primordia. Berlin: Quintessence Publishing Co, Inc.; 1993.

43. Radlanski RJ. Morphogenesis of human tooth primordia: the importance of 3D computer-assisted reconstruction. Int J Dev Biol 1995;39:249-56.

44. Radlanski RJ. Development of the dentition: four-dimensional visualization and open questions concerning the morphogenesis of tooth form and occlusion. Orthod Craniofacial Res 6 (Suppl. 1), 2003:82-8.

45. Ring K et al., Cell Stem Cell. Pour la Science, 2012 (418), p 7.

46. Rohen JW, Yokochi C. Anatomie humaine. Atlas photographique de I'anatomie systématique et topographique. Tome I: Tête, Cou, Tronc. Paris : éditions Vigot, 1985.

47. Saban Y, Poselli R. Atlas of surgical anatomy of head and neck. Paris: Masson, 1994.

48. Sauerland EK, Harper RM. The human tongue during sleep : electromyographic activity of the genioglossus muscle. Exp Neurol 1976;51:160-70.

49. Scott JH. The structure and role of cartilage. In: Dento-facial development and growth. Londres: Pergamon Press, 1967.

50. Sobotta. In: Putz R, Pabts R, éds. Atlas d'anatomie humaine. 3e éd. Tome I. Paris : Éditions Médicales Internationales, 1994.

51. Solow B, Kreiborg S. Soft-tissue stretching: a possible control factor in craniofacial morphogenesis. Scand J Dent Res 1977;85:505507.

52. Sung L.A.: Molecular basis of cell membrane mechanics. In introduction to Bioengineering. World Scientific Publishing Co., Ltd., 2001;Ch.9:217.

53. Talmant J, Talmant JC, Deniaud J. Mécanique de I'enveloppe faciale : 3 - Organisation structurale de I'enveloppe. Rev Orthop Dento Faciale 2000;34:213-43.

54. Talmant J, Deniaud J, Nivet M-H. Ventilation fœtale, ventilation postnatale et morphogenèse. In : Ventilation nasale et dimension verticale : bases morphologiques et physiologiques. Orthod Fr 2003;74(2):147-200.

55. Talmant J, Deniaud J, Nivet M-H. Définition de la " ventilation nasale optimale ». In : La dimension verticale. 1 - Ventilation nasale et dimension verticale : bases morphologiques et physiologiques. Orthod Fr 2003;74(2):201-25.

56. Talmant J, Deniaud J, Nivet MH. Mécanismes posturaux. In : La dimension verticale. 1. Ventilation nasale et dimension verticale : bases morphologiques et physiologiques. Orthod Fr 2003;74(2):227-83.

57. Talmant J, Deniaud J. Du rôle des incisives maxillaires dans le développement de la base du nez. Applications en orthopédie dento-faciale. Orthod Fr 2006;77:19-62. 
58. Talmant J. Aperçu de la physique de la morphogenèse. Orthod Fr 2009;80:291303.

59. Talmant J, Talmant JC, Deniaud J, Amat P. Du traitement étiologique des AOS. Rev Orthop Dento Faciale 2009;43:253-9.

60. Talmant J, Deniaud J. Approche actuelle du traitement des troubles de la ventilation nasale de l'enfant et de l'adolescent. Rev Orthop Dento Faciale 2010;44:285-302.

61. Talmant J. L'orthopédie dento-faciale, une discipline médicale à part entière ? $13^{\circ}$ Journées de l'Orthodontie de la Fédération. Paris, 5-8 novembre 2010.

62. Warwick R, Williams PL. Gray's Anatomy, $35^{\mathrm{e}}$ éd. Londres : Longman, 1973. 